\title{
Plexin-B2 Controls the Development of Cerebellar Granule Cells
}

\author{
Roland H. Friedel, ${ }^{1 \star}$ Géraldine Kerjan, ${ }^{2 \star}$ Helen Rayburn, ${ }^{1}$ Ulrich Schüller, ${ }^{3}$ Constantino Sotelo, ${ }^{2,4}$ \\ Marc Tessier-Lavigne, ${ }^{1}$ and Alain Chédotal ${ }^{2}$ \\ ${ }^{1}$ Department of Biological Sciences, Howard Hughes Medical Institute, Stanford University, Stanford, California 94305 , ${ }^{2}$ Centre National de la Recherche \\ Scientifique, Unité Mixte de Recherche 7102, Université Paris 6, 75005 Paris, France, ${ }^{3}$ Department of Pediatric Oncology, Dana-Farber Cancer Institute, \\ Boston, Massachusetts 02115, and ${ }^{4}$ Cátedra de Neurobiología del Desarrollo “Remedios Caro Almela," Instituto de Neurociencias de Alicante, Universidad \\ Miguel Hernández de Elche, Consejo Superior de Investigaciones Científicas, 03550 San Juan de Alicante, Alicante, Spain
}

Cerebellar granule cell progenitors proliferate postnatally in the upper part of the external granule cell layer (EGL) of the cerebellum. Postmitotic granule cells differentiate and migrate, tangentially in the EGL and then radially through the molecular and Purkinje cell layers. The molecular control of the transition between proliferation and differentiation in cerebellar granule cells is poorly understood. We show here that the transmembrane receptor Plexin-B2 is expressed by proliferating granule cell progenitors. To study Plexin-B2 function, we generated a targeted mutation of mouse Plexin-B2. Most Plexin-B2 ${ }^{-/-}$mutants die at birth as a result of neural tube closure defects. Some mutants survive but their cerebellum cytoarchitecture is profoundly altered. This is correlated with a disorganization of the timing of granule cell proliferation and differentiation in the EGL. Many differentiated granule cells migrate inside the cerebellum and keep proliferating. These results reveal that Plexin-B2 controls the balance between proliferation and differentiation in granule cells.

Key words: cerebellum; granule cell; semaphorin; cell proliferation; plexin; migration

\section{Introduction}

The morphogenetic development of the cerebellum is based on a precisely orchestrated sequence of proliferation and differentiation of its different cell types. Cerebellar granule cells (GCs), by far the most numerous neurons in the cerebellum, play a key role

Received 0ct. 30, 2006; revised Feb. 20, 2007; accepted Feb. 27, 2007.

This work was supported by National Institutes of Mental Health Grant R01MH60612 (Identifying Brain Wiring Mechanisms by Gene Trapping) and from National Heart, Lung, and Blood Institute (NHLBI) Grant U01HL66600 (the NHLBI-Bay Area Functional Genomics Consortium) (M.T.-L. and S. K. McConnell). A.C. was supported by the Fondation pour la Recherche sur le Cerveau and the Association pour la Recherche sur le Cancer, R.H.F was supported by the Deutsche Forschungsgemeinschaft, U.S. was supported by a fellowship from the Dr. Mildred-Scheel-Stiftung für Krebsforschung, and C.S. was supported by Spanish Ministry of Education and Science Grant SAF2004-07990). We thank S. K. McConnell (Stanford University, Stanford, CA) for support and advice, W. Havran (Scripps Research Institute, La Jolla, CA), and C. Goodnow (Australian National University, Canberra, New South Wales, Australia) for Plexin-B2 antibodies, D. Karagogeos (University of Crete, Chania, Greece) for TAG-1 antibody, F. Qiu (University of Medicine and Dentistry of New Jersey, Piscataway, NJ) for Barhl1 CDNA, A. P. McMahon for Gli1 CDNA, M. Ruat for Shh and Smoothened, and M. Wassef (École Normale Supérieure, Paris, France) for Math1 cDNA. We also thank R. Schwartzmann and V. Georget (Service d'Imagerie IFR83, Université Paris 6, Paris, France) for their help with confocal and video microscopy and X. Lu (University of Virginia, Charlottesville, VA) for the design of the targeted trapping vector.

${ }^{*}$ R.H.F. and G.K. contributed equally to this work.

M.T.-L. and A.C. are co-senior authors.

Correspondence should be addressed to either of the following: Dr. Alain Chédotal, Centre National de la Recherche Scientifique, Unité Mixte de Recherche 7102, Université Paris 6, 9 Quai Saint Bernard, 75005 Paris, France, E-mail:alain.chedotal@snv.jussieu.fr; or Dr. Marc Tessier-Lavigne, Genentech Inc., 1 DNA Way, South San Francisco, CA 94080, E-mail: marct|@gene.com.

M. Tessier-Lavigne's present address: Genentech Inc., 1 DNA Way, South San Francisco, CA 94080.

R. H. Friedel's present address: Institute of Developmental Genetics, GSF-Research Center, Ingolstädter Landstraße 1, 85764 Neuherberg, Germany.

U. Schüller's present address: Zentrum für Neuropatholgie der LMU, Feodor-Lynen-Straße 23, 81377 München, Germany.

DOI:10.1523/JNEUROSCI.4710-06.2007

Copyright $\odot 2007$ Society for Neuroscience $\quad 0270-6474 / 07 / 273921-12 \$ 15.00 / 0$ in this process. In mice, granule cell progenitors (GCPs) are born from embryonic day 13 (E13) in rhombic lip (Wingate, 2005) and migrate tangentially over the cerebellar plate to form a secondary proliferating zone, the external granule cell layer (EGL). The proliferation of granule cell progenitors is controlled by several secreted proteins such as bone morphogenetic proteins (BMP), stromal cell-derived factor 1 (SDF-1), and Sonic Hedgehog (Shh) (Alder et al., 1999; Dahmane and Ruiz i Altaba, 1999; WechslerReya and Scott, 1999; Klein et al., 2001; Blaess et al., 2006; Corrales et al., 2006). Postmitotic granule cells migrate tangentially in the EGL before descending along Bergmann glia to settle in the internal granule cell layer (IGL) (Yacubova and Komuro, 2003). The molecular mechanisms that control the switch from proliferation to differentiation in cerebellar granule cells is essentially unknown.

Plexins are a family of transmembrane proteins that have been originally characterized for their role in axon guidance. More recently, they were also shown to control cell migration, immune response, and blood vessel growth (Kruger et al., 2005). Plexins are a major component of the receptor complexes for semaphorins (Gherardi et al., 2004). In vertebrates, nine Plexin genes, distributed into four subclasses (A-D) have been identified (Tamagnone et al., 1999; Hartwig et al., 2005). Type-B Plexins (B1-B3) are widely expressed in developing and adult mice (Perala et al., 2005). In vitro experiments have suggested that B-Plexins can be activated by class 4 semaphorins (Kruger et al., 2005). Moreover, signaling downstream of B-Plexins, in particular Plexin-B1, is beginning to be well characterized in transfected cells and involves small GTPases (Oinuma et al., 2004b; Toyofuku et al., 2005). Although the physiological importance of A-, C- and 
D-Plexins in vivo has been primarily validated by the phenotypic analysis of knock-out mice (Pasterkamp et al., 2003; Gu et al., 2005; Suto et al., 2005; Yaron et al., 2005), the in vivo function of $\mathrm{B}-\mathrm{Plexins}$ remains unknown. In the developing mouse nervous system, the highest levels of Plexin-B2 mRNAs are detectable in the ventricular zone of the telencephalon and in the EGL (WorzFeld et al., 2004). To determine the function of Plexin-B2 in cerebellum development, we generated a targeted mutation of the mouse Plexin- $B 2$ gene.

We report here that the Plexin-B2 mutation results in two different phenotypes, depending on the genetic background. In the C57BL/6 inbred strain, Plexin-B2 ${ }^{-/-}$mutants develop a cephalic neural tube closure defect, accompanied by perinatal lethality. In the CD1 outbred strain, many Plexin- $B 2^{-/-}$mutants survive and display a profoundly altered layering and foliation of the cerebellum. These defects are correlated with a major disorganization of the EGL: the timing of granule cell proliferation and differentiation is abnormal, and cells expressing markers of differentiated granule cells migrate inside the cerebellum and keep proliferating for several more days.

\section{Materials and Methods}

Animals. Swiss and C57BL/6 mice (Janvier, Le Genest-St. Isle, France) were used for simple expression studies.

Postnatal day 0 (P0) to P5 mice were anesthetized on ice and, after P5, by inhalation of isofluorane Foren (Abbott Laboratories, Abbott Park, IL). The day of birth corresponds to P0. All animal procedures were performed in accordance with institutional guidelines.

Generation of Plexin-B2-deficient mice. The Plexin-B2 gene was mutated by targeted trapping as described previously (Friedel et al., 2005). Briefly, the targeted trapping construct was constructed by flanking the placental alkaline phosphatase (PLAP) secretory trap cassette (Leighton et al., 2001) with $5^{\prime}$ and $3^{\prime}$ homology arms (5 and $3 \mathrm{~kb}$, respectively), which were generated by PCR from genomic DNA of E14Tg2a.4 embryonic stem (ES) cells using the Expand High Fidelity PCR system (Roche, Indianapolis, IN). Correct homologous recombination resulted in the insertion of the secretory trap cassette between exons 16 and 17 (exon containing start codon is 1 ). Exons on the $5^{\prime}$ homology arm were sequenced to control for potential nonsense mutations.

The construct was electroporated into the feederless E14Tg2a.4 ES cell line, and drug-resistant clones were selected with $125 \mu \mathrm{g} / \mathrm{ml} \mathrm{G418} \mathrm{(cat-}$ alog \#11811-031; Invitrogen, Carlsbad, CA) for $10 \mathrm{~d}$. A $1 \mathrm{~kb} 5^{\prime}$ external probe was used to screen for correct homologous recombination events by Southern blot analysis (112 of 118 clones positive). Before blastocyst injection, selected ES cell clones were confirmed by Southern blot analysis with an internal neo probe and by genomic PCR with a 3' external primer.

Two mouse lines of different genetic background were established by continuously backcrossing heterozygous males to either C57BL/6 or CD1 females (Charles River Laboratories, Wilmington, MA).

PCR genotyping was performed with a common forward primer $\left(5^{\prime}\right.$ gccattgagaagctttgtcaggtg), a wild-type specific reverse primer $\left(5^{\prime}\right.$ gcaaacttctggatgaggctgaag), and a mutant specific reverse primer ( $5^{\prime}$ - acttccggagcggatctcaaactc). The official allele name [Mouse Genome Informatics (The Jackson Laboratory, Bar Harbor, ME)] is Plxnb2 $2^{\text {tmlMatl }}$.

Math1:GFP;Plexin-B2 mice were obtained by crossing Plexin-B2deficient mice with transgenic mice expressing the green fluorescent protein (GFP) under the Math1 (mouse atonal homolog 1) promoter (Lumpkin et al., 2003).

Histology. Brains were collected as described previously (Marillat et al., 2002). Brain sections were incubated with antibodies against $\beta$-galactosidase ( $\beta$-gal) (1:1000; Cappel, West Chester, PA), calciumbinding protein calbindin-D 28K (CaBP) (1:1000; Swant, Bellizona, Switzerland), phospho-histone-H3 (H3P) (1:1000; Cell Signaling Technology, Beverly, MA), Plexin-B2 (1:2000; gift from Dr. Havran, Scripps

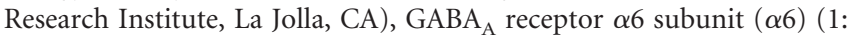
1000; Chemicon, Temecula, CA), parvalbumin (1:1000; Sigma, St. Louis,
$\mathrm{MO}$ ), vesicular glutamate transporter 2 (vGlut2) (1:3000; Chemicon), semaphorin 6A (mSema6A) (1:200; R \& D Systems, Minneapolis, MN), TAG-1 (transient axonal glycoprotein 1) (1:3000), glial fibrillary acid protein (GFAP) (1:400; Chemicon), laminin (1:500; Sigma), Pax6 (paired box gene 6) (polyclonal 1:1000; Chemicon), Pax6 (monoclonal 1:10; Developmental Studies Hybridoma Bank, University of Iowa, Iowa City, IA), nestin (1:500; Chemicon), retinoid orphan receptor $\alpha(\mathrm{ROR} \alpha)$ (1:500; Santa Cruz Biotechnology, Santa Cruz, CA), activated-caspase-3 (1:250; Cell Signaling Technology), NCL-Ki67 (1:1000; Novocastra Laboratories, Newcastle upon Tyne, UK), Doublecortin (Dcx) (1:1000; Chemicon), and Zicl (zinc finger protein of the cerebellum 1) (1:3000 gift from Dr. Rosalind Segal, Dana-Faber Institute, Boston, MA), followed by species-specific secondary antibodies (Jackson ImmunoResearch, West Grove, PA). Sections were counterstained with Hoechst 33258 (10 $\mu \mathrm{g} / \mathrm{ml}$; Sigma), mounted in Mowiol (Calbiochem, La Jolla, $\mathrm{CA}$ ), and examined with a fluorescent microscope (DM6000; Leica, Nussloch, Germany) or a fluorescent confocal microscope (DM IRBE; Leica). Histochemical stainings for the $\beta$-gal and PLAP reporters were performed as described previously (Leighton et al., 2001). All comparisons and quantifications were done on sections of comparable mediolateral levels and within lobules IV to VIII.

Plexin-B2 antibody production. For Western Blot analysis, we used a rabbit antiserum that had been raised against a $\mathrm{N}$-terminal peptide (EYGSIPVDINKKIKQD) of Plexin-B2 (1:1000; a kind gift from Dr. Goodnow, Australian National University, Canberra, New South Wales, Australia). For immunohistochemistry, we used an Armenian hamster monoclonal antibody (clone 3E7) that had been raised against the extracellular domain of Plexin-B2 (1:2000; a kind gift from Dr. Havran).

Bromodeoxyuridine staining and quantification of cell proliferation. $\mathrm{P} 0$, P11, P13, P15, or P27 mice were injected intraperitoneally with bromodeoxyuridine (BrdU) (15 mg/ml, $50 \mathrm{mg} / \mathrm{kg}$ body weight; Sigma) diluted in a saline solution. Animals were perfused 1 or $3 \mathrm{~h}$ (short pulse labeling) or $24 \mathrm{~h}$ after injection. Brain sections were incubated $30 \mathrm{~min}$ at $37^{\circ} \mathrm{C}$ in $2 \mathrm{~N} \mathrm{HCl}$ in $\mathrm{PBS}$ before immunohistochemistry with a rat antiBrdU antibody (1:100; Harlan, Indianapolis, IN). To count BrdUpositive cells at $\mathrm{P} 11$, when proliferation rate is maximal, we realized $60 \times$ confocal microscopy acquisitions (stacks of $2 \mu \mathrm{m}$ deep). At P15, when proliferation is lower, we counted the total number of BrdU-positive cells per section. To quantify the proportion of Ki67 and BrdU double-labeled cells at P15, we realized $60 \times$ confocal microscopy acquisitions (stacks of $2 \mu \mathrm{m}$ deep) of superficial regions of cerebellum. To quantify H3Ppositive cells at $\mathrm{P} 0$, we counted both the total number of positive cells per section (expressed in square millimeters) and the number of positive cells in the more superficial regions of cerebellum (expressed by millimeters of EGL), within $60 \times$ confocal microscopy fields (stacks of $2 \mu \mathrm{m}$; expressed in millimeters of EGL length), on 10 sagittal and nonadjacent sections.

In situ hybridization. Antisense riboprobes were labeled with digoxigenin-11UTP (DIG) as described previously (Marillat et al., 2002) by in vitro transcription of cDNAs encoding mouse Math1 (a gift from M. Wassef, École Normale Supérieure, Paris, France) (de Diego et al., 2002), Barhl1 (BarH-like 1) (a gift from F. Qiu, University of Medicine and Dentistry of New Jersey, Piscataway, NJ) (Li et al., 2004), Shh, Smoothened, Gli1 (glioma-associated oncogene homolog 1) or Plexin-B2 [DNA fragment from mouse expressed sequence tagged homologous to amino acids 1479-1721 in hPlexin-B2 (KIAA0315)] (Cheng et al., 2001). Templates for class 4 semaphorin probes were synthesized by reverse transcription-PCR from cDNA of P0 mouse brain and cloned into pCRII-TOPO (Invitrogen). In situ hybridizations were performed as described previously (Marillat et al., 2002).

Statistical analysis. For all statistical analysis, the significance was calculated by ANOVA (Statview; Abacus Concepts, Calabasas, CA). Each quantitative value represents mean \pm SEM.

\section{Results}

\section{Generation of mutation in the Plexin-B2 gene by targeted trapping}

To study the role of transmembrane proteins in neural development, we applied a targeted mutagenesis strategy that uses a promoterless gene trap vector to efficiently target candidate genes 

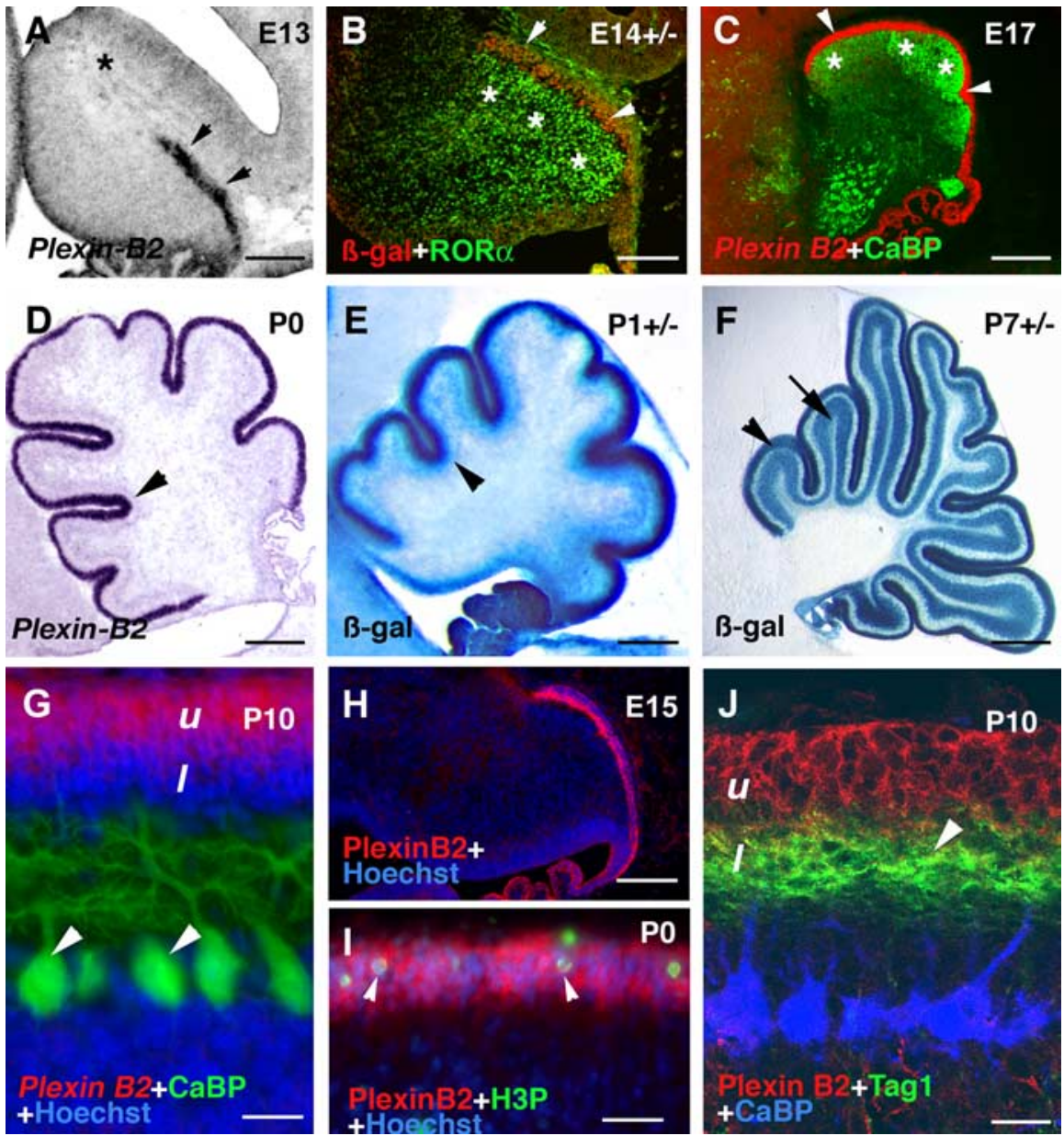

Figure 1. Plexin-B2 expression pattern in the developing cerebellum. All sections are sagittal. $A, A t E 13$, in situ hybridization with a DIG-labeled Plexin- $B 2$ riboprobe showed that Plexin- $B 2 \mathrm{mRNA}$ is highly expressed in the developing EGL (arrowheads) but is not expressed in the nuclear transitory zone (asterisk). $B$, E14 Plexin-B2 ${ }^{+/-}$cerebellum immunostained for $\beta$-gal and ROR $\alpha$. $\beta$-gal is highly expressed in the EGL (arrowheads) above ROR $\alpha$-positive migrating Purkinje cells (asterisks). The weak staining in the ventricular zone is not specific. C,AtE17, Plexin-B2 mRNA is still detected in the EGL (arrowheads) above CaBP-labeled Purkinje cells (asterisks). Plexin-B2 signal has been artificially colored in red using Photoshop (Adobe Systems, San Jose, CA) and superimposed to the $C$ aBP labeling. D, At P0, Plexin-B2 transcripts are highly expressed in the EGL (arrowhead). $E, \beta$-gal expression is also confined to the EGL (arrowhead) in the cerebellum of P1 Plexin- $B 2^{+/-} . \boldsymbol{F}$, In P7 Plexin-B2 ${ }^{+/-}$cerebellum, $\beta$-gal expression is observed in both the EGL (arrowhead) and IGL (arrow). G, At P10, CaBP-positive Purkinje cells (arrowheads) form a monolayer. Plexin-B2 mRNA is only detected in the upper EGL (u) and not in the lower EGL (I). Plexin-B2 signal has been artificially colored in red using Photoshop and superimposed to the $\mathrm{CaBP}$ and Hoechst labeling. $\boldsymbol{H}, \boldsymbol{J}$, Wild-type cerebellum sections immunostained with anti-Plexin-B2 antibodies. $\boldsymbol{H}$, AtE15, Plexin-B2 is only detected in the EGL and choroid plexus (Hoechst counterstaining). $\boldsymbol{I}, \mathrm{PO}$ section labeled for Plexin-B2, H3P, and Hoechst. In the EGL, mitotic cells labeled with H3P (arrowheads) also express Plexin-B2.J, P10 section immunostained for Plexin-B2, CaBP, and TAG-1. Plexin-B2 is expressed in the upper EGL, whereas TAG-1 is found in the lower EGL and top of the upper part of the molecular layer above CaBP-positive Purkinje cells. Scale bars: $\boldsymbol{A}, 130 \mu \mathrm{m} ; \boldsymbol{B}, 160 \mu \mathrm{m}$; C, $220 \mu \mathrm{m} ; \boldsymbol{D}, 200 \mu \mathrm{m} ; \boldsymbol{E}, 300 \mu \mathrm{m} ; \boldsymbol{F}, 550 \mu \mathrm{m} ; \boldsymbol{G}, 18 \mu \mathrm{m} ; \boldsymbol{H}, 120 \mu \mathrm{m} ; \boldsymbol{I}, 35 \mu \mathrm{m}(I)$.

("targeted trapping”) (Friedel et al., 2005). The targeted trap of the mouse Plexin-B2 gene was generated with a targeting construct that led to the insertion of the secretory trap vector (Leighton et al., 2001) into the intron between exons 16 and 17 (supplemental Fig. 1, available at www.jneurosci.org as supplemental material). This insertion creates a fusion transcript of the first 16 exons of Plexin-B2 with the elements of the secretory trap vector, consisting of a transmembrane domain/ $\beta$-geo ( $\beta$-gal fused to neo) cassette, followed by an internal ribosomal entry sequence and a PLAP sequence (supplemental Fig. 1, available at www. jneurosci.org as supplemental material). Fusion proteins of the secretory trap vector are retained in intracellular compartments and cannot act on the cell surface (Mitchell et al., 2001). By Northern and Western blot analysis of Plexin-B2 $2^{-1-}$ mutants, no wild-type mRNA or proteins were detected, indicating efficient splicing of the splice acceptor of the secretory trap vector (supplemental Fig. 1, available at www. jneurosci.org as supplemental material). We therefore predict that the targeted trap of Plexin-B2 results in a functional null mutation.

Plexin-B2 mutation causes neural tube closure defects

We bred the Plexin-B2 targeted trap allele for four generations into the inbred C57BL/6 strain. In this genetic background, almost all homozygous mutant embryos were found with cephalic neural tube closure defects (supplemental Fig. 2, available at www.jneurosci.org as supplemental material), which led to exencephaly and neonatal lethality. This phenotype was caused by a failure of fusion of the neural head folds during a critical period at approximately E8.5. We used the $\beta$-gal reporter to study the expression of Plexin-B2 at this time point and observed a high expression in the ridges lining the head folds (supplemental Fig. 2, available at www.jneurosci.org as supplemental material). We also observed in some of the Plexin-B2 $2^{-1-}$ mutants additional closure defects of the posterior neuropore, ranging in severity from a curled tail to spina bifida aperta (supplemental Fig. 2, available at www.jneurosci.org as supplemental material). Heterozygous animals appeared to be fully viable, with no detectable phenotype. In parallel to breeding with the C57BL/6 strain, we also introduced the Plexin-B2 mutation into the CD1 outbred strain. Outbred strains, which are genetically heterogeneous populations, have higher physical strength and lower neonatal lethality than inbred strains. After one generation backcross to the CD1 genetic background, neural tube closure defects occurred with reduced frequency, and, after four generations of backcross to CD1, $\sim 30 \%$ of Plexin-B2 $2^{-/-}$mutants were fully viable and fertile.

\section{Plexin-B2 is expressed by proliferating granule} cell progenitors

It has been reported previously that Plexin-B2 mRNA is highly expressed in the cerebellar EGL (Worz-Feld et al., 2004). To study the expression of Plexin-B2 in the developing cerebellum in more detail, we used in situ hybridization for Plexin-B2 mRNA, immunostaining for Plexin-B2, and also the genetic reporters $\beta$-gal and PLAP. In the embryonic mouse cerebellum, Plexin-B2 mRNA was first detected at E13 in the choroid plexus of the fourth ventricle and in the primordium of the EGL that contains the first granule cell progenitors migrating over the cerebellar plate from the rhombic lip (Fig. 1A). Later on (E14-E17), simultaneously with the extension of the EGL, Plexin-B2 mRNAs and $\beta$-gal were 
detected all along the expanding EGL at the surface of the cerebellum (Fig. $1 B, C$ ). At P0-P1, Plexin-B2 and $\beta$-gal were evenly expressed throughout the whole EGL (Fig. $1 D, E)$, but $\beta$-gal was also detectable in the IGL. This slight difference between Plexin-B2 mRNA expression and $\beta$-gal reporter activity (also seen at later stages, see below) is most likely attributable to the perdurance of the $\beta$-gal protein after the normal extinction of the Plexin-B2 mRNA and protein. Such a phenomenon has been described before for other gene trap lines (for instance, see Kerjan et al., 2005) as a result of the stability of the reporter protein. At P7-P10, Plexin-B2 and $\beta$-gal were still highly expressed in the EGL but also at a low level in the IGL (Fig. $1 F, G$ ). The EGL becomes subdivided into two layers around birth, when the first granule cells leave the cell cycle: a superficial layer containing proliferating granule cell progenitors (upper EGL) and a deeper layer containing tangentially migrating postmitotic granule cells (lower EGL). On P10 sections, Plexin-B2 mRNA was confined to the upper EGL (Fig. 1G). Plexin-B2 protein expression was next studied with an anti-Plexin-B2 monoclonal antibody. In the E15 cerebellum, strong Plexin-B2 immunoreactivity was found in the EGL and choroid plexus (Fig. $1 H$ ). At P0, double staining for Plexin-B2 and the mitotic marker $\mathrm{H} 3 \mathrm{P}$ revealed that Plexin-B2 was expressed by proliferating granule cell progenitors (Fig. 1I). At P10, Plexin-B2 protein was detected on proliferating cells in the upper EGL but not on postmitotic granule cells expressing TAG-1 in the lower EGL (Fig. 1J). In the adult cerebellum, low levels of Plexin-B2 mRNA could be detected in the IGL by radioactive in situ hybridization (data not shown) and by the $\beta$-gal and PLAP reporters (Fig. $2 F, G$ ).

In conclusion, our data show that Plexin-B2 is highly expressed by proliferating granule cell progenitors.

\section{Plexin-B2 mutation causes cerebellar defects: the adult phenotype}

Viable Plexin-B2 $2^{-1-}$ mutants in the CD1 background displayed no obvious behavioral or motor deficits, but the gross morphology of their cerebellum was severely altered. First, cerebella of adult Plexin$B 2^{-1-}$ mutants were often smaller than those of control littermates (65-100\% of control size; data not shown). Second, major foliation defects were obvious with adult cerebella stained in toto for $\beta$-gal histochemistry (Fig. $2 A, B$ ) and on sagittal sections immunostained for $\alpha 6$, a marker of mature granule cells (Kerjan et al., 2005) (Fig. $2 C, D$ ). In Plexin- $B 2^{-/-}$mutants, the precentral (ce) and intercrural (i) fissures were absent, and lobules I-III and VI-VII were
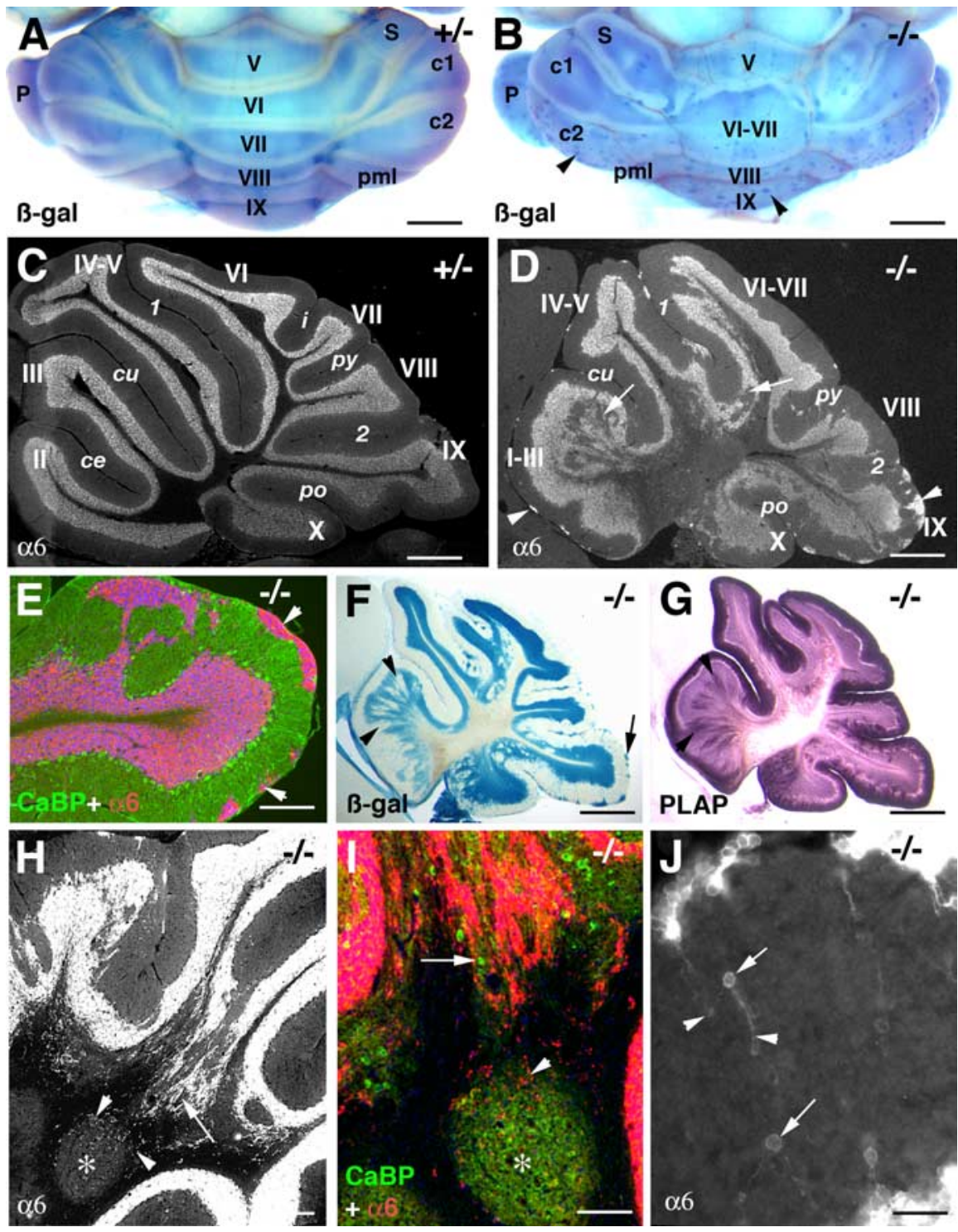

Figure 2. Cerebellar defects in Plexin-B2-deficient mice. Adult cerebella from Plexin- $B 2^{+/-}$mice $(A, C)$ and Plexin- $B 2^{-1-}$ mice $(\boldsymbol{B}, \boldsymbol{D}-\boldsymbol{J}) . \boldsymbol{A}, \boldsymbol{B}$, Cerebella were stained in toto for $\beta$-gal histochemistry. Vermis lobes are indicated by Roman numerals. In Plexin- $B 2^{-1-}$, the foliation is altered, some folia are fused (VI-VII), some fissures are absent, and others are less pronounced. In addition, ectopic $\beta$-gal-expressing cell clusters are found at the cerebellar surface (arrowhead). C, D, Sagittal cerebellum sections immunostained with anti- $\alpha 6$. In Plexin-B2 ${ }^{-1-}$, lobules I-III and VI-VII are fused and the cerebellar lamination is profoundly perturbed. The precentral fissure (ce) and intercrural fissure (i) are absent. Islands of $\alpha 6$-unlabeled cells (arrows) are intermingled with $\alpha 6$-expressing granule cells. Ectopic clusters of $\alpha 6$-positive granule cells are found at the cerebellar surface (arrowheads). $\boldsymbol{E}$, Higher magnification of a section double stained for $\alpha 6$ and CaBP. $\alpha 6$-positive granule cells are intermingled with CaBP-positive Purkinje cells. The arrowheads point to the superficial clusters of granule cells. $\boldsymbol{F}, \beta$-gal staining also revealed the profound disorganization of the cerebellum and the islands of $\beta$-gal-negative cells. $\boldsymbol{G}$, A section immediately adjacent to $\boldsymbol{F}$ was stained for PLAP. PLAP is expressed by parallel fibers in the molecular layer and in the $\beta$-gal-negative islands (arrowhead, compare with $\boldsymbol{F}$ ). $\boldsymbol{H}, \boldsymbol{I}$, The base of some cerebellar folia is completely disorganized, and some dispersed $\alpha 6$-positive granule cells (arrowheads) invade the deep nuclei (asterisk) containing the CaBP-positive Purkinje cells axons. Some ectopic Purkinje cells are also found in the white matter (arrow in $I$ ). $J$, In the molecular layer of the less disorganized lobules, a few ectopic $\alpha 6$-positive granule cells (arrows) with two emerging dendrites (arrowheads) can be observed. Scale bars: $\boldsymbol{A}, \boldsymbol{B}, 1.2 \mathrm{~mm} ; \boldsymbol{C}, \boldsymbol{D}, 445 \mu \mathrm{m} ; \boldsymbol{E}, 200 \mu \mathrm{m} ; \boldsymbol{F}, \mathbf{G}, 650$ $\mu \mathrm{m} ; \boldsymbol{H}, 240 \mu \mathrm{m} ; I, 120 \mu \mathrm{m} ; J, 40 \mu \mathrm{m}$. S, Simplex; c1, crus1; C2, crus2; cu, culmen; pml, paramedial lobe; 1, primary fissure; py, prepyramidal fissure; 2 , secondary fissure; po, posterior fissure; $p$, paraflocculus.

fused. The other fissures were less pronounced, and most folia had an irregular shape. We also observed in all Plexin-B2 ${ }^{-1-}$ cerebella a midline cleft of lobule $X$, possibly resulting from a fusion defect of the cerebellar plates (supplemental Fig. 3, available at www.jneurosci.org as supplemental material). Third, many ectopic clusters of granule cells expressing $\beta$-gal and $\alpha 6$ 

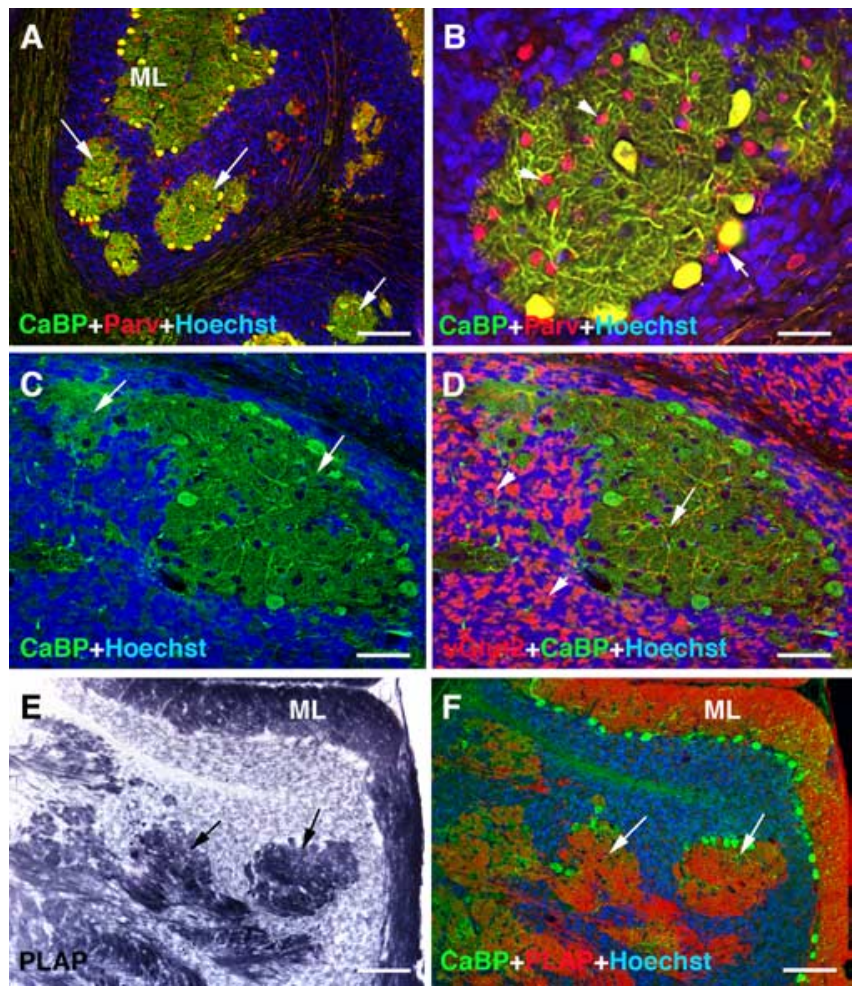

Figure 3. Cerebellum structure in Plexin-B2-deficient mice. Sagittal sections from adult Plexin- $B 2^{-1-}$ mice. $A, B$, Sections immunostained for $C a B P$ and parvalbumin and counterstained with Hoechst. $A$, Parvalbumin-labeled molecular layer interneurons are localized in the islands of ectopic CaBP-expressing Purkinje cells (arrows), dispersed among Hoechst-labeled granule cells. B, Higher magnification of a Purkinje cell island. Parvalbumin-positive interneurons are intermingled in Purkinje cell dendrites (arrowheads), and some typical basket cell "pinceaux" (arrow) are observed at the base of Purkinje cell bodies at the interface with granule cells. $\boldsymbol{C}, \boldsymbol{D}$, Section immunostained for $\mathrm{CaBP}(\boldsymbol{C})$ and vGlut2 $(\boldsymbol{D})$ and counterstained with Hoechst. Ectopic (aBP-positive Purkinje cells (arrows in $\boldsymbol{C}$ ) are contacted by vGlut2-labeled climbing fibers (arrows in $\boldsymbol{D}$ ), whereas vGlut2-labeled mossy fiber rosettes (arrowheads in $\boldsymbol{D}$ ) are found on granule cells. $E$, $F$, Section stained for PLAP histochemistry and immunostained for CaBP and counterstained with Hoechst. In $\boldsymbol{F}$, PLAP staining was converted to red color using Photoshop. $\boldsymbol{E}$, PLAP expression is concentrated in the molecular layer (ML, parallel fibers) and in the islands of ectopic Purkinje cells (arrows in $\boldsymbol{E}, \boldsymbol{F}$ ). Scale bars: $\boldsymbol{A}, 240 \mu \mathrm{m} ; \boldsymbol{B}-\boldsymbol{D}, 60 \mu \mathrm{m} ; \boldsymbol{E}, \boldsymbol{F}, 130 \mu \mathrm{m}$.

were found at the cerebellum surface (Fig. $2 A-F, J$ ). Fourth, the structure of the IGL and Purkinje cell layers were extremely perturbed, mainly in the rostral and caudal folia (Fig. $2 D-G$ ). The cerebellar cortex was fragmented into multiple groups or islands of Purkinje cells (identified by calbindin, CaBP, immunoreactivity) that were embedded in $\alpha 6$-positive granule cells. At the base of some folia, the IGL was almost completely absent, Purkinje cells were found in the white matter, and some granule cells even invaded the deep nuclei (Fig. $2 \mathrm{H}, \mathrm{I}$ ). In the less affected folia, Purkinje cells were well aligned, their morphology unaffected, and only a few ectopic granule cells were observed in the molecular layer (Fig. $2 J$ ).

\section{Cerebellum circuitry in Plexin-B2 mutants}

Although the Plexin-B2 mutation causes a severe disruption of the laminar architecture of the cerebellar cortex, we found that the overall arrangement of cerebellar neurons and axons was preserved. In the ectopic islands of Purkinje cells, molecular layer interneurons identified by parvalbumin immunostaining were detected at their usual position among Purkinje cell dendritic trees. and some typical basket cell "pinceaux" were observed at the base of Purkinje cell somata (Fig. $3 A, B$ ).
To examine precerebellar projections to the cerebellar cortex, we used immunostaining for the vesicular glutamate transporter vGlut2 (Kerjan et al., 2005), which labels climbing fibers that synapse on Purkinje cell dendrites and mossy fibers that contact granule cell dendrites in structures called glomeruli. vGlut 2 staining on Plexin- $B 2^{-1-}$ cerebellum showed that the cell-type specificity of these connections was maintained even in the ectopic islands: climbing fibers contacted Purkinje cells, and mossy fibers rosettes were only found next to granule cells (Fig. $3 C, D$ ). Moreover, in Plexin- $B 2^{-/-}$mutants, parallel fibers visualized by PLAP staining were confined to Purkinje cell dendrites in the ectopic islands and in the molecular layer in the less affected folia (Figs. $2 G, 3 E, F)$.

\section{Bergmann glia, basal lamina, and granule cell migration}

The presence of ectopic granule cell clusters at the cerebellar surface has been reported previously in several mouse models that displayed a loss of the subependymal basal lamina (Graus-Porta et al., 2001). This basal lamina provides an anchorage for the end feet of the radial Bergmann glia cells, which are a substrate for the radially migrating early postmitotic granule cells. We therefore tested for the integrity of the basal lamina by immunostaining for laminin and for the integrity of the radial glia network by immunostaining for GFAP and nestin. At E18, no major difference was observed in the organization of the radial glia palisade between Plexin-B2 ${ }^{+/-}$and Plexin-B2 $2^{-/-}$(data not shown). At P11 and in adults, the palisade of radial glia was perturbed in Plexin-B2 ${ }^{-/-}$ cerebellum with many fibers having curved and irregular courses. However, GFAP-labeled radial glia fibers still extended to the pial surface and formed characteristic end feet (Fig. $4 A-D, G, H$ ). In the cerebellum of P11 Plexin-B2 ${ }^{-/-}$mice, Pax6-immunopositive granule cells were frequently observed apposed to Bergmann glia fibers, suggesting that radial migration was not altered (Fig. $4 G, H)$. Accordingly, only a few ectopic cells remain close to the surface or in the molecular layer in the adult mutant cerebellum (Fig. 2). Last, the expression and distribution of the extracellular matrix protein laminin was identical in Plexin- $B 2^{+/-}$and Plexin$B 2^{-/-}$, both at $\mathrm{P} 15$ and in adults (Fig. $4 C-F$ ). These results suggest that Plexin-B2 deficiency does not cause major granule cells migration defects.

\section{Development of the Plexin-B2 ${ }^{-/-}$phenotype}

To better determine the origin of cerebellum defects, we next analyzed early cerebellum development in Plexin- $B 2^{-1-}$ mutants. In all cases, the cerebella of heterozygous Plexin- $B 2^{+/-}$ animals were identical to wild type. At E14, we found no major differences in the arrangement of the EGL between Plexin- $B 2^{-/-}$ and Plexin-B2 $2^{+/-}$cerebella (Fig. $5 A-D$ ). At E17, the cerebellar distribution of Pax6-expressing cells, which is very variable along the rostrocaudal and mediolateral axis even in wild-type, still appears comparable in Plexin-B2 ${ }^{+-}$and Plexin-B2 ${ }^{-1-}$ (Fig. $5 E, F)$. However, the whole-mount observation of E17 cerebella from Math1:GFP;Plexin-B2 ${ }^{+-}$and Math1:GFP;Plexin-B2-1showed that the cerebellum from homozygous mutants lacks a rostral fissure (Fig. $5 G, H$ ). Despite this slightly delayed foliation, the expression pattern of the transcription factor Math1 (also known as Atoh1 and HATH1) was similar to controls, with Math1-expressing cells only positioned at the cerebellar surface throughout its anteroposterior extent (Fig. 5I,M). This suggests that the initial tangential migration of granule cell progenitors was not primarily affected in Plexin-B2 ${ }^{-/-}$mutants. However, the use of markers for early postmitotic granule cells revealed some important abnormalities. The two transmembrane pro- 
teins Sema6A and TAG-1 are expressed by postmitotic granule cells that migrate in the lower EGL (Kerjan et al., 2005). At P0, in Plexin-B2 $2^{+/-}$and Plexin- $B 2^{-/-}$mice, Sema6A was expressed in a high-anterior to low-posterior gradient, whereas TAG-1 was homogeneously expressed (Fig. $5 J, L, N, O)$. However, in Plexin-B2 $2^{-/-}$ mice, ectopic Sema6A- and TAG-1expressing cells were also found deep inside the cerebellar parenchyma (Fig. $5 \mathrm{~N}-$ $P)$. Moreover, the upper and lower EGL often overlapped (Fig. 5P). This disorganization of the EGL architecture was also observed with immunostaining for the Zic1 transcription factor (Aruga et al., 2002) (supplemental Fig. 3, available at www.jneurosci.org as supplemental material). Likewise, in P0 Plexin-B2 ${ }^{+/-}$mice, PLAPexpressing cells were only detected in the upper EGL above Purkinje cells that were arranged in a thick multilayer (Fig. 5Q,R). In Plexin-B2 $2^{-/-}$mice, PLAP-expressing cells were also found in the EGL, but many of them were localized inside the cerebellar plate, intermingled with CaBP-positive Purkinje cell bodies (Fig. 5S,T, inset in $S$ ). This suggests that, in mice deficient for Plexin-B2, the organization of the EGL is perturbed and that some granule cells migrate prematurely into the cerebellar parenchyma.

\section{Abnormal granule cell proliferation in Plexin-B2-deficient mice}

In the newborn cerebellar cortex of Plexin- $B 2^{+/-}$mice, granule cell proliferation is mainly confined to the upper part of the EGL, as seen with the cell proliferation marker Ki67 (Fig. 6A) or BrdU pulse labeling (animals killed $3 \mathrm{~h}$ after BrdU injection) (Fig. 6C). We confirmed the identity of granule cells by costaining for Pax6 (Fig. 6C). Some proliferating cells (Pax6 negative) were also observed outside the EGL and most likely correspond to precursors for molecular interneurons and oligodendrocytes. In contrast, in Plexin-B2 $2^{-/-}$mutants, the EGL was less compact, and proliferating Pax6-positive granule cells expressing Ki67 or labeled by BrdU and Pax6 were scattered throughout the entire EGL (Fig. $6 B, D)$ but also outside the EGL, in the cerebellar parenchyma (Fig. $6 B, D$ ). We next asked whether the scrambled architecture of the EGL in Plexin-B2 mutants would correlate with a change in the overall proliferation rate. The quantification of the number of cells expressing the M-phase marker H3P in the EGL or total cerebellum (Fig. 6E,F) showed that, at $\mathrm{P} 0$, the number of mitotic cells was slightly lower in Plexin-B2 ${ }^{-/-}$mice $(9.2 \pm 0.9 \mathrm{H} 3 \mathrm{P}-$ positive cells/mm of EGL and $89.8 \pm 4.4 \mathrm{H} 3 \mathrm{P}$-positive cells/ $\left.\mathrm{mm}^{2}\right)$ than in Plexin-B2 ${ }^{+/-}(13.8 \pm 2.0 \mathrm{H} 3 \mathrm{P}$-positive cells $/ \mathrm{mm}$ of EGL and $117.9 \pm 8.4 \mathrm{H3P}$-positive cells $/ \mathrm{mm}^{2} ; n=10$ intermediate rostrocaudal positions; see Materials and Methods; $p<$ 0.01 ). These results suggest that the presence of proliferating and mitotic cells streaming away from the EGL in newborn Plexin$B 2^{-1-}$ cerebellum is not attributable to an initial excessive proliferation.

Interestingly, the difference in proliferation rate between mutant and control cerebella reversed at later stages of development. In P11 Plexin-B2 $2^{-1-}$ cerebellum, there was a small but not signif$50 \mu \mathrm{m} ; \boldsymbol{E}, \boldsymbol{F}, 220 \mu \mathrm{m} ; \boldsymbol{G}, \boldsymbol{H}, 35 \mu \mathrm{m}$.
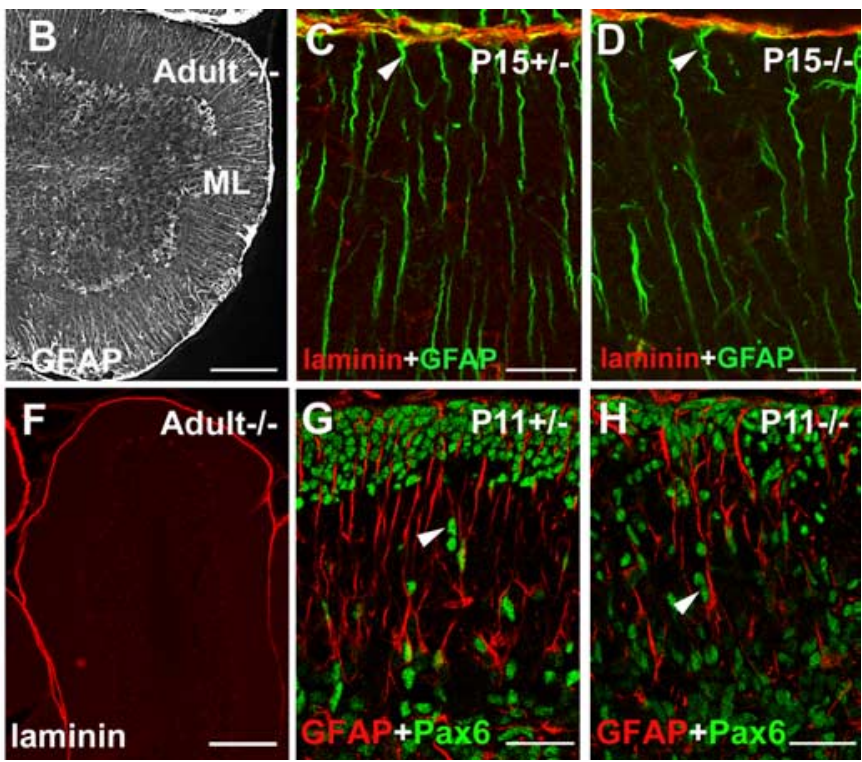

Figure 4. Radial glia, basal lamina, and granule cell migration in Plexin-B2-deficient mice. $\boldsymbol{A}-\boldsymbol{H}$, Sagittal cerebellum sections PaP $(\boldsymbol{A}-\boldsymbol{D}, \mathbf{G}, \boldsymbol{H})$, laminin $(\boldsymbol{C}-\boldsymbol{F})$, and Pax6 $(\boldsymbol{G}, \boldsymbol{H})$. Normal radial glia palisade in adult $(\boldsymbol{A}), \mathrm{P} 15(\boldsymbol{C}), \operatorname{or} \mathrm{P} 11(\boldsymbol{G})$ GFAP-positive radial glia fibers both in Plexin-B2 $2^{+/-}$and in Plexin-B2 ${ }^{-/-}$(arrowheads in $\mathbf{G}, \boldsymbol{H}$ ). Scale bars: $\boldsymbol{A}, \boldsymbol{B}, 270 \mu \mathrm{m} ; \boldsymbol{C}, \boldsymbol{D}$

icant increase in the number of $3 \mathrm{~h}$ BrdU pulse-labeled cells in the EGL (Figs. 7A, 8I). This difference in proliferation rate had significantly increased at P13 (Fig. $7 C, D$ ) and P15 (Figs. $7 G, H$, $8 \mathrm{~J}, \mathrm{~K})$. Last, to test whether increased cell proliferation at $\mathrm{P} 15$ is attributable to GCPs reentering into the cell cycle instead of exiting it, we determined the percentage of cells double labeled with Ki67 (expressed by cells active in the cell cycle) and BrdU (animals killed $24 \mathrm{~h}$ after injection) or only labeled with BrdU (Chenn and Walsh, 2002). The GCPs that had differentiated or remained dormant will only express BrdU but not Ki67. In Plexin-B2 $2^{-1-}$ cerebella, $52.6 \pm 2.1 \%$ ( $n=2$ animals $)$ of BrdU-labeled cells also expressed Ki67 and thus reentered the cell cycle, showing no significant difference compared with Plexin-B2 $2^{+/-}$cerebella $(58.2 \pm 4.6 \% ; n=2$ animals; $p>0.2)$.

\section{Sustained proliferation of migrating granule cells in Plexin-B2 mutants}

In control P11 and P13 mice, the microtubule-associated protein Dcx is expressed by postmitotic granule cells migrating tangentially in the lower EGL or migrating radially in the molecular layer (Dcx) (Fig. $7 A, C$ ). In contrast, in Plexin-B2 $2^{-/-}$mutants, cells of the upper and lower EGL were intermingled, and many Dcxexpressing cells reached the pial surface (Fig. $7 B, D$ ). Intriguingly, in mutant cerebella, Dcx-positive cells that were also positive for the proliferation markers Ki67 (Fig. $7 B, D$, inset in $D$ ), H3P (Fig. $7 E, F)$, or BrdU (data not shown) were found in the molecular layer. Moreover, at P13, rings of Ki67-labeled cells were found at the periphery of Purkinje cells islands (Fig. $8 A, B, E$ ). These proliferating cells were granule cells because they expressed Pax 6 or Math1:GFP (Fig. $8 E$ and data not shown). If they were displaced granule cell progenitors similar to those found in the EGL of wild-type and Plexin-B2 $2^{+/-}$mice, they should highly express mRNAs for the transcription factor Barhl1 (Li et al., 2004) (Fig. 

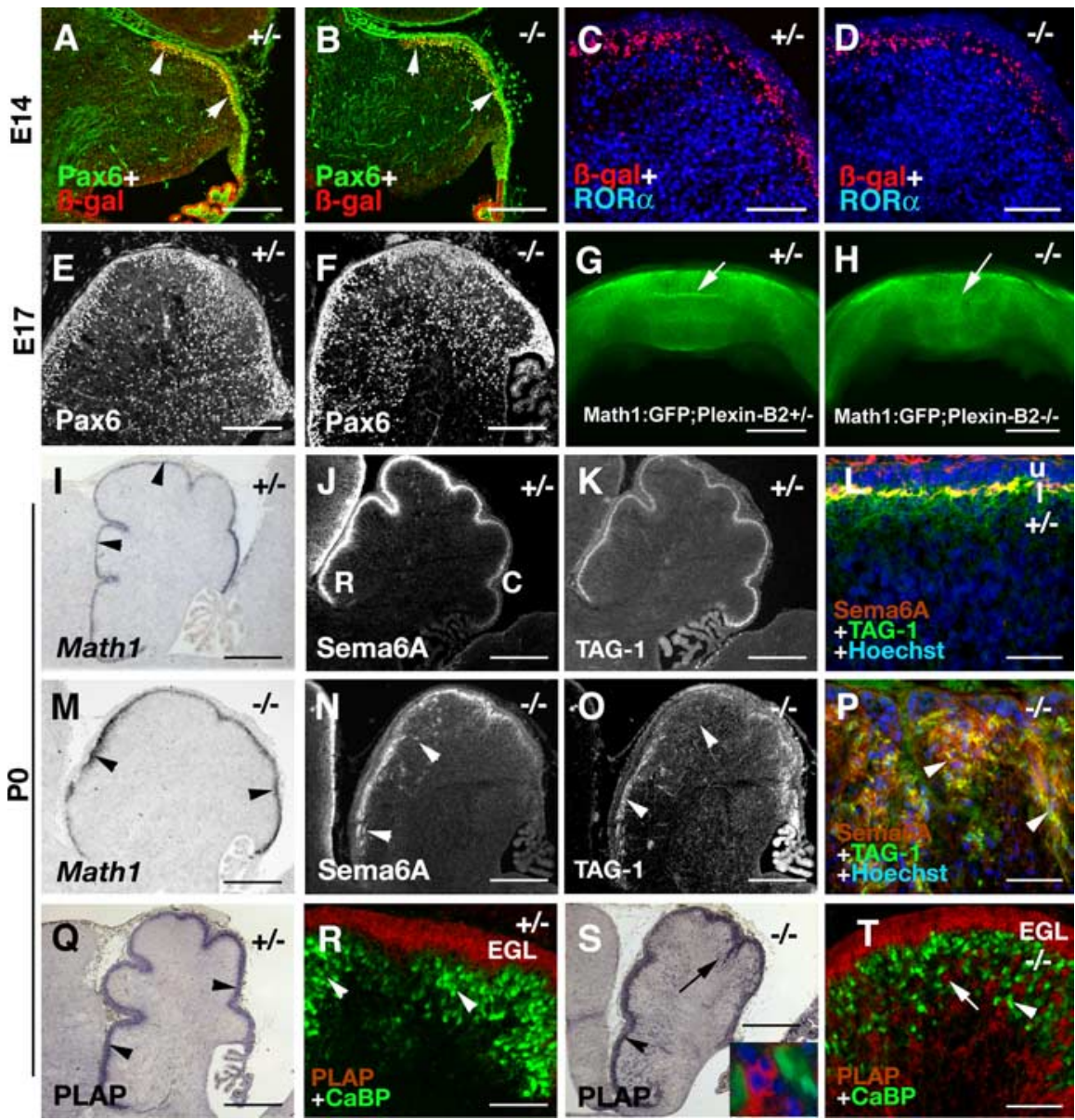

Figure 5. Development of cerebellar defects in Plexin-B2-deficient mice. Sagittal sections of the cerebellum of Plexin-B2 ${ }^{+/-}$ $(\boldsymbol{A}, \boldsymbol{C}, \boldsymbol{E}, \boldsymbol{G}, \boldsymbol{I}-\boldsymbol{L}, \boldsymbol{Q}, \boldsymbol{R})$ and Plexin-B2 $2^{-/-}(\boldsymbol{B}, \boldsymbol{D}, \boldsymbol{F}, \boldsymbol{H}, \boldsymbol{M}-\boldsymbol{P}, \boldsymbol{S}, \boldsymbol{T})$ mice. $\boldsymbol{A}, \boldsymbol{B}$, Section of $\mathrm{E} 14$ embryos immunostained with Pax6 and $\beta$-gal antibodies. The development of the EGL (arrowheads) and the distribution of granule cell progenitors coexpressing Pax6 and $\beta$-gal is similar in Plexin-B2 $2^{+/-}$and Plexin-B2 ${ }^{-/-}$mice. $C, D$, Higher magnification of the EGL of E14 cerebellum double labeled with $\beta$-gal and ROR $\alpha$ antibodies. In both Plexin-B2 ${ }^{+/-}(\boldsymbol{C})$ and Plexin-B2 $2^{-1-}(\boldsymbol{D})$ cerebella, $\beta$-gal-expressing granule cell progenitors are restricted to the EGL above ROR $\alpha$-positive Purkinje cells. $E, F, A t E 17$, Pax6 expression pattern in the cerebellum is comparable in Plexin-B2 $2^{+/-}(\boldsymbol{E})$ and Plexin-B2 $2^{-/-}(\boldsymbol{F}) . \mathbf{G}, \boldsymbol{H}$, GFP expression in whole-mount cerebella from E17 Math1: GFP;Plexin-B2 ${ }^{+/-}(\boldsymbol{G})$ and Math1:GFP;Plexin-B2 ${ }^{-/-}(\boldsymbol{H})$ mice. A fissure (arrow) is lacking on the rostral cerebellum of Plexin-

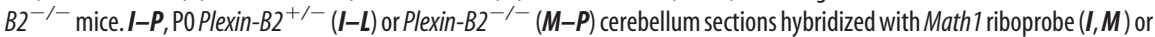
immunostained with Sema6A $(\boldsymbol{J}, \boldsymbol{L}, \boldsymbol{N}, \boldsymbol{P})$ and TAG-1 $(\boldsymbol{K}, \boldsymbol{L}, \mathbf{O}, \boldsymbol{P})$ antibodies. $\boldsymbol{I}$, Math1 mRNA is only expressed in granule cell progenitors in the EGL (arrowheads). $J-L$, Sema6A and TAG-1 are expressed in postmitotic granule cells in the lower EGL (lin $L$ ) and not in the upper EGL ( $u$ in $\boldsymbol{L}$ ). However, although Sema6A is expressed in a decreasing anteroposterior gradient, TAG-1 is homogeneously expressed in the EGL. $\boldsymbol{M}$, In Plexin- $B 2^{-/-}$cerebellum, Math1 mRNA expression is still confined to the EGL that has a normal anteroposterior distribution (arrowheads). $\boldsymbol{N}-\boldsymbol{P}$, Likewise, Sema6A and TAG- 1 are still coexpressed, and Sema6A expression respects its normal gradient. However, Sema6/TAG-1-immunostained cells are also observed outside the EGL in the cerebellar parenchyma (arrowheads in $\mathbf{N}, \mathbf{0}$ ). In addition, the upper and lower EGL are mixed, and streams of TAG-1/Sema6A-expressing cells invade the cerebellum (arrowheads in P). $\mathbf{Q}, \boldsymbol{R}$, Section of P0 Plexin- $B 2^{+/-}$cerebellum stained for PLAP and immunolabeled for $\mathrm{CaBP}(\boldsymbol{R})$. In $\boldsymbol{R}$, PLAP staining was converted to red color with Photoshop. PLAP-expressing cells are restricted to the EGL (arrowheads in $\mathbf{Q}$ ) and never observed in (aBP-positive Purkinje cells (arrowheads in $\boldsymbol{R}$ ). $S, T$, In PO Plexin-B2 ${ }^{-1-}$, the foliation is less pronounced. Most PLAP-expressing cells are in the EGL (arrowhead in S), but many are also detected within the cerebellar parenchyma (arrow in S). $\boldsymbol{T}$, The ectopic PLAP-expressing granule cells (arrow) are intermingled with CaBP-positive Purkinje cell bodies (arrowhead; inset in S). Scale bars: $\boldsymbol{A}, \boldsymbol{B}, \boldsymbol{E}, \boldsymbol{F}, 175 \mu \mathrm{m} ; \boldsymbol{C}, \boldsymbol{D}, 150 \mu \mathrm{m} ; \mathbf{G}, \boldsymbol{H}, 880 \mu \mathrm{m} ; \mathbf{I}-\boldsymbol{K}, \boldsymbol{M}-\mathbf{0}, \mathbf{Q}, \mathbf{S}, 300 \mu \mathrm{m} ; \boldsymbol{L}, \boldsymbol{P}, 45 \mu \mathrm{m}$; $R, T, 80 \mu \mathrm{m}$.

8 F) and Math1 (Fig. 8C). However, Barhl1 expression at the periphery of Purkinje cell islands was low, similar to IGL cells (Fig. $8 G, H)$. In addition, Math1-expressing cells were never detected in the cerebellar parenchyma outside of the EGL (Fig. 8D) (see also Fig. 5M). This suggests that ectopically proliferating granule cells at the periphery or Purkinje cell islands may not be equivalent to granule cell progenitors found normally in the upper EGL. The increase in granule cell proliferation and the ectopic prolif- eration caused by Plexin-B2 deficiency were transient. No proliferating cells were detected in the cerebellar cortex of mice at P27 or older as determined by Ki67 staining (data not shown). Last, there was also no increased cell death in the P15 cerebellum of Plexin-B2-deficient mice as determined by anti-activated caspase- $3 \mathrm{immu}$ nostaining $\left(8.02 \pm 0.6\right.$ positive cells $/ \mathrm{mm}^{2}$ in Plexin-B2 $2^{+/-}$and $11.7 \pm 2.6$ positive cells $/ \mathrm{mm}^{2}$ in Plexin-B2 ${ }^{-/-} ; n=2$ animals; $p>0.2$ ), suggesting that the granule cells born from ectopic proliferation were viable.

\section{Expression and function of class 4 semaphorins in the EGL}

To get a better understanding of the mechanism of action of Plexin-B2 in EGL cells, we first studied the expression patterns of its putative semaphorin ligands. So far, only class 4 semaphorins and Sema5A have been shown to bind type-B Plexins (Perrot et al., 2002; Artigiani et al., 2004; Masuda et al., 2004). However, Sema5A does not bind to Plexin-B2 (Artigiani et al., 2004). There are seven known class 4 semaphorins in vertebrates, six of which (Sema4A, 4B, 4C, 4D, 4F, and 4G) were described in rodents. We have shown previously that Sema4D is only expressed by oligodendrocytes in the postnatal brain (Moreau-Fauvarque et al., 2003) and thus may not be a Plexin-B2 ligand in the EGL. We studied the expression pattern of the five other class 4 semaphorins at P10, the peak of granule cell proliferation. Sema4A was expressed at a low level in the Purkinje layer (supplemental Fig. 4, available at www.jneurosci.org as supplemental material). Sema4B was also expressed in the Purkinje cell layer but most likely by Bergman glia cells and not by Purkinje cells (supplemental Fig. 4, available at www. jneurosci.org as supplemental material, compare with Sema4G staining of Purkinje cells). Sema4C and Sema4F were weakly expressed mostly in the lower part of the EGL and in the IGL (supplemental Fig. 4, available at www.jneurosci.org as supplemental material). Last, Sema4G was expressed by Purkinje cells. We next analyzed cerebellum organization in mice single or double deficient for the class 4 semaphorins Sema4A (Kumanogoh et al., 2005) and Sema4D (Kumanogoh et al., 2002), which are all viable and have no obvious brain defect. We first stained sections from P30 cerebellum with Nissl or antibodies against CaBP, neuronalspecific nuclear protein, and $\alpha 6$. Neither cerebellar defects nor ectopic granule cells were observed in Sema4A, Sema4D, and Sema4A/Sema4D double knock-outs (supplemental Fig. 4, available at www.jneurosci.org as supplemental material) (data not shown). 

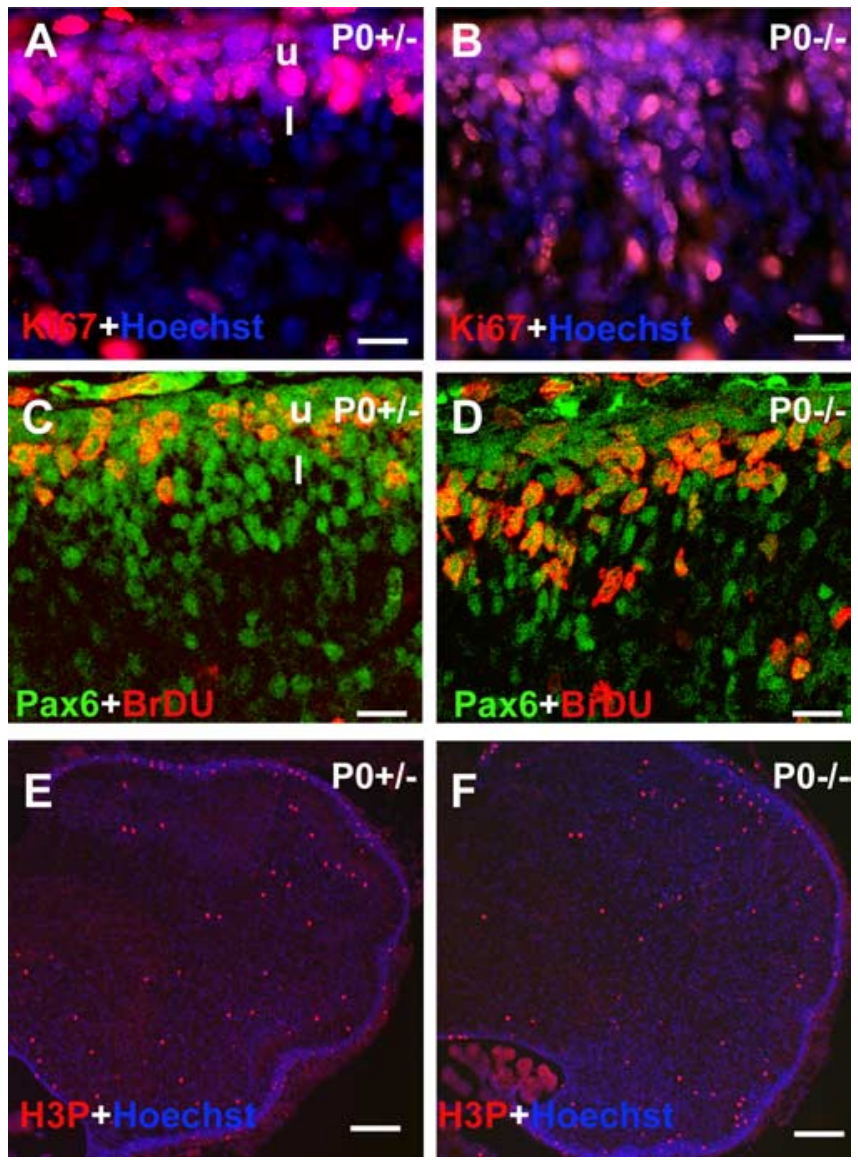

Figure 6. Cell proliferation in neonatal Plexin-B2-deficient mice. Sagittal sections from $P O$ Plexin-B2 ${ }^{+/-}(\boldsymbol{A}, \boldsymbol{C}, \boldsymbol{E})$ and Plexin-B2 $2^{-/-}(\boldsymbol{B}, \boldsymbol{D}, \boldsymbol{F})$ mice immunostained for Ki67 $(\boldsymbol{A}, \boldsymbol{B})$, Pax6 and $\operatorname{BrdU}(C, D)$, or $\mathrm{H3P}(\boldsymbol{E}, \boldsymbol{F})$ and counterstained with Hoechst $(\boldsymbol{A}, \boldsymbol{B}, \boldsymbol{E}, \boldsymbol{F}) . A, C$, In Plexin$B 2^{+/-}$mice, proliferating granule cell progenitors labeled with Ki67 and BrdU are mostly found in the upper EGL (u), whereas postmitotic granule cells (only Pax6 and Hoechst labeled) start to appear in the lower EGL (I). Some proliferating cells (Pax6 negative) are also found outside the EGL and most likely correspond to precursors for molecular interneurons and oligodendrocytes $(\boldsymbol{B}, \boldsymbol{D})$. In contrast, in Plexin-B2 ${ }^{-1-}$ animals, the upper and lower EGL are not segregated, and proliferating Pax6-positive granule cells are also observed away from the EGL deeper inside the cerebellar cortex.E, $\boldsymbol{F}, \mathrm{H} 3 \mathrm{P}$ immunostaining in P0 cerebellum. Scale bars: $\boldsymbol{A}-\boldsymbol{D}, 17 \mu \mathrm{m} ; \boldsymbol{E}, \boldsymbol{F}, 120$ $\mu \mathrm{m}$.

\section{Discussion}

Plexin-B2 controls the balance between proliferation and differentiation in granule cell progenitors

During CNS development, neurons are generated from proliferating progenitor cells located in the ventricular and subventricular zones (Ohnuma and Harris, 2003). Cerebellar granule cells that arise from displaced progenitors in the EGL are the most noticeable exception (Wingate, 2005). Like other neurons, cerebellar GCs are permanently postmitotic neurons that will not reenter the cell cycle once they leave the EGL. Thus, the sequence of progenitor proliferation, neuronal migration, and differentiation are precisely choreographed, and abnormal proliferation may lead to abnormal differentiation or migration and vice versa. However, the molecular mechanisms that trigger GC differentiation and simultaneously stop the proliferation of GCPs are almost completely unknown.

A plethora of transcription factors such as Hes (hairy and enhancer of split), Numb, Zic1, Ziprol (zinc finger proliferation 1), Pax6, Math1 and NeuroD (Wingate, 2005) control either GCP proliferation or differentiation in the EGL. These two processes
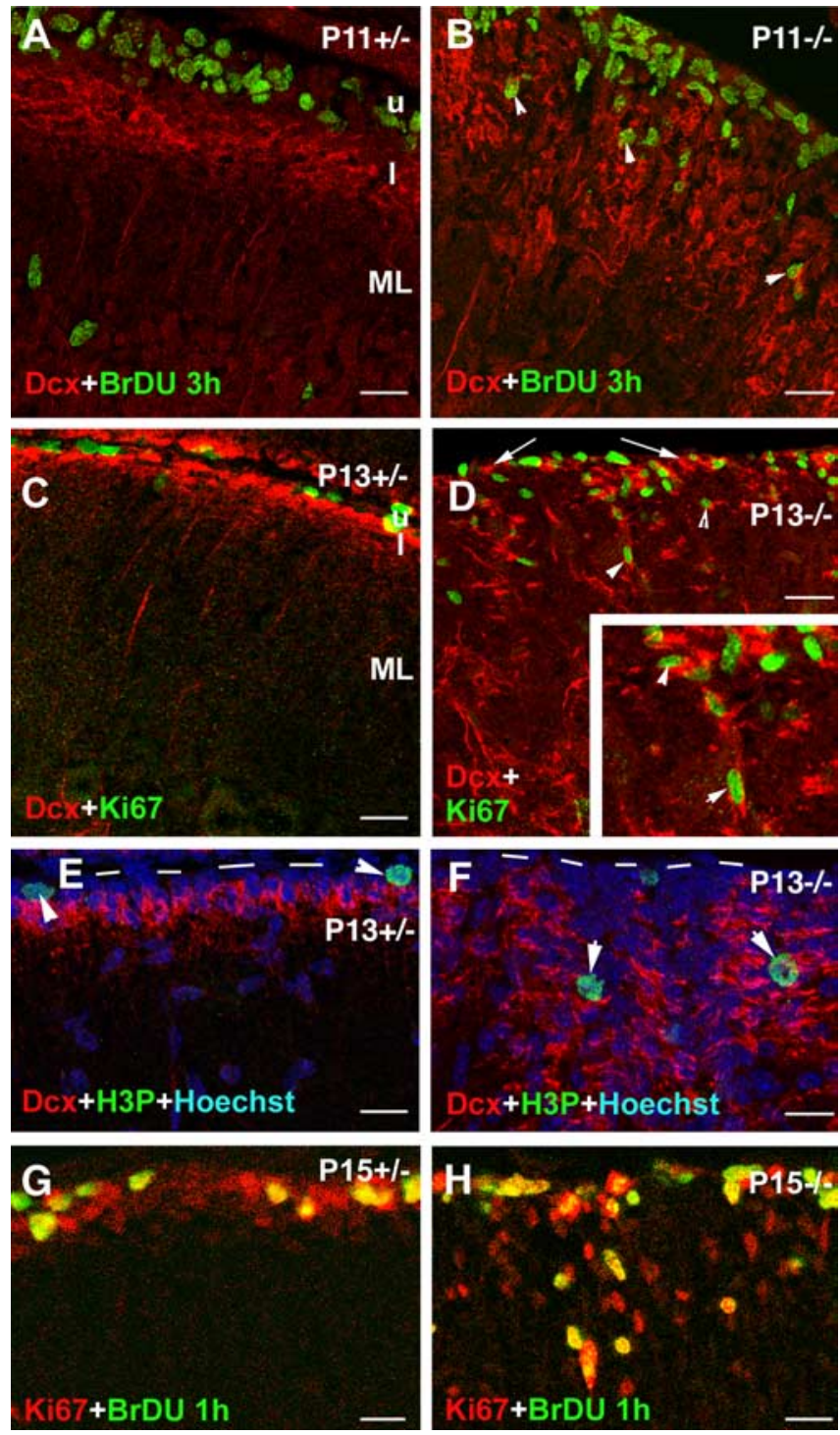

Figure 7. EGL defects in postnatal Plexin-B2-deficient mice. All sections are sagittal. $A-D_{\text {, }}$ P11 $(\boldsymbol{A}, \boldsymbol{B})$ or P13 (C-F) cerebellum sections of Plexin-B2 ${ }^{+/-}(\boldsymbol{A}, \boldsymbol{C}, \boldsymbol{E})$ and Plexin-B2 ${ }^{-/-}(\boldsymbol{B}, \boldsymbol{D}$, F) mice immunostained for $D c x$ and $B r d U$ (injected $3 \mathrm{~h}$ before fixation; $A, B)$ or Ki67 $(C, D)$ or $\mathrm{H3} P$ $(\boldsymbol{E}, \boldsymbol{F})$. In the EGL of Plexin-B2 ${ }^{+/-}$, BrdU-labeled cells and Ki67- or H3P-immunoreactive cells are only found in the upper EGL ( $u$; arrowhead in $E$ ), whereas $D c x$ is expressed in the lower $E G L$ (I) and molecular layer (ML). In contrast, in Plexin-B2 ${ }^{-1-}$, BrdU-, H3P-, or Ki67-labeled cells are also found in the molecular layer (arrowheads in $\boldsymbol{B}, \boldsymbol{D}, \boldsymbol{F}$ ), whereas $D(x$-immunoreactive cells are observed near the pial surface (arrows in $\boldsymbol{D}$ ). Note also the reduction of size of the EGL between P11 and P13 in Plexin-B2 ${ }^{+/-}, \boldsymbol{G}, \boldsymbol{H}, \mathrm{P} 15$ cerebellum sections of Plexin-B2 ${ }^{+/-}(\boldsymbol{G})$ and Plexin-B2 $2^{-1-}(\boldsymbol{H})$ mice immunostained for Ki67 and BrdU (injected $1 \mathrm{~h}$ before fixation). In Plexin-B2 ${ }^{-1-}$, many double-labeled cells are observed away from the pial surface. Scale bars: $A-D, 25 \mu \mathrm{m} ; E-H, 15 \mu \mathrm{m}$.

are also influenced by several diffusible factors such as Sonic Hedgehog, neurotrophins, and BMPs (Lindholm et al., 1997; Alder et al., 1999). Plexin-B2 function simultaneously influences both the proliferation of GCPs and the differentiation/migration of postmitotic GCs. In postnatal Plexin-B2 ${ }^{-/-}$mice, staining with markers for the cells of the upper and lower EGL reveals that the two layers are primarily intermingled and that granule cell differentiation occurs prematurely. However, most Plexin-B2 $2^{-/-}$ GCs leave the EGL, migrate inside the cerebellum, and project parallel fibers on Purkinje cell dendrites. Thus, once initiated, granule cell differentiation seems to proceed normally in Plexin- 

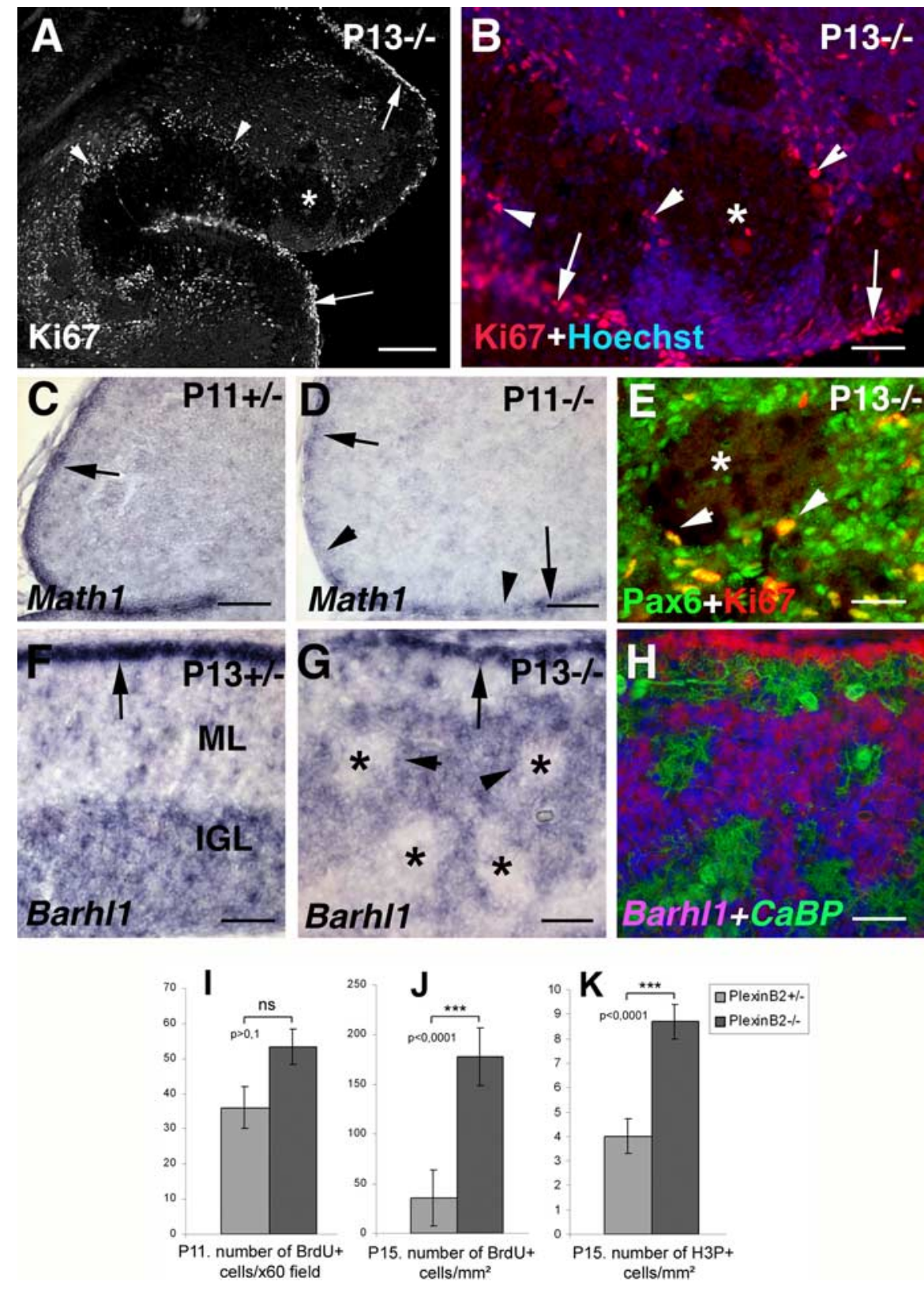

Figure 8. Ectopic granule cell proliferation in Plexin-B2-deficient mice. All sections are sagittal. $A, B, E$, P13 Plexin-B2 ${ }^{-/}$ cerebellum immunostained for Ki67 and Hoechst $(\boldsymbol{B})$ and Pax6 $(\boldsymbol{E})$. Ki67-labeled proliferating cells are found in the EGL (arrows in $\boldsymbol{A}, \boldsymbol{B})$ but also in the periphery of Purkinje cell islands (asterisks) at the interface with granule cells (arrowheads). Most Ki67positive cells are also labeled for Pax6 (arrowheads in $\boldsymbol{E}$ ). C, D, P11 Plexin-B2 ${ }^{+-}(\boldsymbol{C})$ and Plexin-B2 ${ }^{-/-}(\boldsymbol{D})$ cerebella hybridized with a Math1 riboprobe. Math1 expression is only detected in the EGL (arrows). In Plexin-B2 ${ }^{-1-}$, gaps in Math1 expression are also observed (arrowheads in $\boldsymbol{D}$ ). $\boldsymbol{F}-\boldsymbol{H}$, P13 Plexin-B2 ${ }^{+-}(\boldsymbol{F})$ and Plexin-B2 ${ }^{-/-}(\boldsymbol{G}, \boldsymbol{H})$ cerebellum hybridized with Barhl1 riboprobe. In $\boldsymbol{H}$, Barhl1 signal has been converted to red color with Photoshop and superposed to CaBP immunostaining and Hoechst staining. In Plexin-B2 ${ }^{+/-}$, Barlh1 mRNA is highly expressed in granule cell progenitors in the EGL (arrow) and at a low level in the molecular layer (ML) and IGL. Barh/1 expression is also very high in the EGL of Plexin-B2-/- (arrow) and at a low level the IGL and at the periphery (arrowheads) of the ectopic islands of CaBP-positive Purkinje cells (asterisks). $\boldsymbol{I}-\boldsymbol{K}$, Quantifications of the number of proliferating cells at P11 $(I)$ or P15 $(\boldsymbol{J}, \boldsymbol{K})$ revealed by short-term BrdU pulse labeling $(\boldsymbol{I}, \boldsymbol{J}$; see Materials and Methods) or H3P immunostaining ( $\boldsymbol{K})$. Number of cells are expressed by millimeters of sections $(\boldsymbol{J}, \boldsymbol{K})$ or by $60 \times$ microscope field (I; see Materials and Methods). Statistics are based on $n=2$ animals for each cases. Scale bars: $\boldsymbol{A}, 150 \mu \mathrm{m} ; \boldsymbol{B}, 60 \mu \mathrm{m} ; \boldsymbol{C}, \boldsymbol{D}, 30 \mu \mathrm{m}$; $E, 20 \mu \mathrm{m} ; \boldsymbol{F}-\boldsymbol{H}, 40 \mu \mathrm{m}$.

$B 2^{-/-}$mutants. Last, in Plexin- $B 2^{-/-}$mutants, although radial migration from the EGL starts too early, GCs appear to follow radial glia fibers in vivo. However, the presence of ectopic GCs in the molecular layer suggests that some GCs were unable to complete their migration to the IGL. In addition, some ectopic GCs are localized in the deep nuclei, suggesting that they were unable to stop in the IGL. The variable penetrance of the Plexin-B2 phenotype between lobules and GCs cannot be simply explained by functional redundancy between type-B Plexins, because Plexin-B1 and Plexin-B3 are not expressed in the developing cerebellar cortex (A. Chédotal and G. Kerjan, unpublished data). Therefore, in absence of Plexin-B2, the basic migration machinery is likely functional, but its regulation is probably impaired.

In addition to perturbing the timing of granule cell differentiation, Plexin-B2 deficiency affects the timing of GCP proliferation, which, in Plexin-B2 $2^{-/-}$animals, is first lower at birth and then higher from P11 on. This shifted GCP proliferation period probably explains the abnormal cerebellar foliation observed in Plexin-B2 ${ }^{-1-}$ mutants (Mares and Lodin, 1970; Millen et al., 1995). More importantly, proliferating cells that express markers of differentiated GCs are found in Plexin-B2 $2^{-/-}$mutants within the cerebellum parenchyma and around ectopic Purkinje cells. This result suggests that the regulation of GCP proliferation and granule cell differentiation can be uncoupled. In other words, in the absence of Plexin-B2, GC differentiation and migration can start independently of cell cycle exit. This is surprising because recent studies suggested that the EGL was a mitogenic niche for GCPs and that cell cycle exit might be induced by moving GCPs away from the EGL (Choi et al., 2005). The abnormal positioning of Purkinje cells contributes to the disorganization of cerebellum architecture in Plexin-B2 mutants. Purkinje cells and GCs development is interdependent. Therefore, although Purkinje cells do not express Plexin-B2, their migration and differentiation are probably altered because of the disorganization of the EGL, the premature migration of granule cells, and the invasion of Purkinje cell bodies by dividing GCs before their final alignment into a monolayer (Fig. 9).

\section{Proliferation of differentiated granule} cells in Plexin-B2-deficient mice

Although the phenotype of Plexin-B2 mutant mice is somehow reminiscent of the phenotype described in mice deficient for CXCR4 (chemokine C-X-C receptor 4) or SDF-1 (Ma et al., 1998; Zou et al., 1998; Lu et al., 2001; Vilz et al., 2005), there are important differences that do not support the conclusion that SDF-1 signaling is perturbed. First, cerebellar defects appear much earlier in SDF-1/CXCR4 mutants. Second, in SDF-1/ CXCR4 mutants, the invasion of the embryonic cerebellum by ectopic GCPs is massive, whereas it is more dispersed in Plexin- 


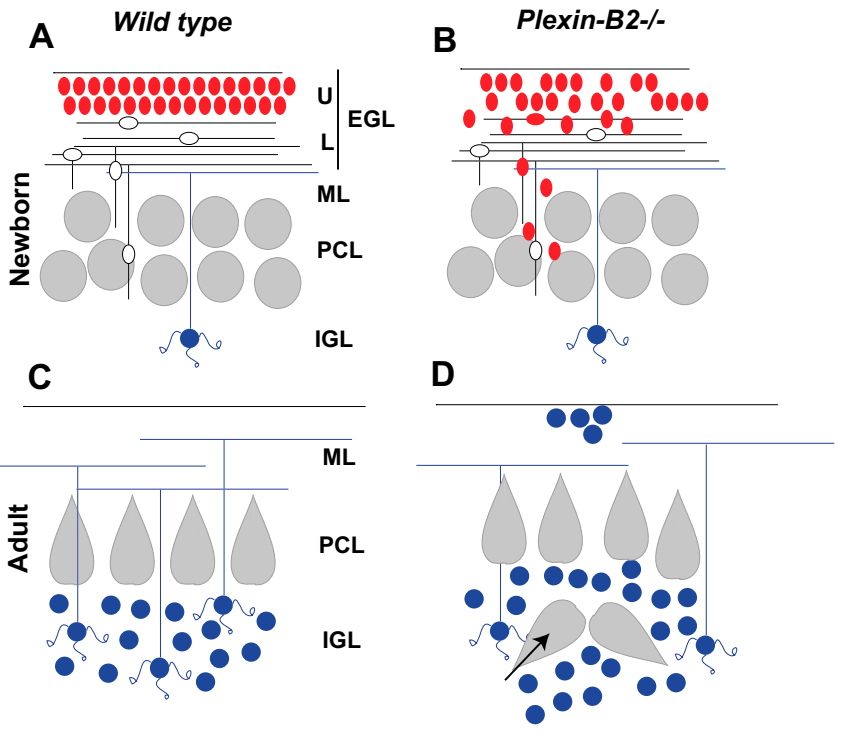

Figure 9. Model of Plexin-B2 function in the developing cerebellum. $\boldsymbol{A}$, In newborn wildtype mice, granule cell progenitors (in red) proliferate exclusively in the upper EGL (U). Postmitotic granule cells start differentiating and migrate in the lower $E G L(L)$ before migrating radially through the molecular layer $(\mathrm{ML})$ and the Purkinje cell layer $(\mathrm{PCL})$ to the $\mathrm{IGL}$. At this stage, Purkinje cells (in gray) are still distributed in multiple layers. $\boldsymbol{B}$, In newborn Plexin-B2 mutants, cells of the upper and lower EGL are intermingled, and cells expressing markers of differentiated granule cells divide during their migration in the molecular layer and also inside the Purkinje cel layers. $\boldsymbol{C}$, In adult mice, Purkinje cells are aligned in a monolayer, above differentiated granule cell bodies (in blue), all localized in the IGL. D, In adult Plexin-B2 mutants, some ectopic granule cells are found at the top of the molecular layer and the cerebellar cortex is fragment. Islands of Purkinje cells (arrow) are embedded in differentiated granule cells.

$B 2^{-/-}$mice. More importantly, in SDF-1/CXCR4 mutants but not in Plexin-B2 ${ }^{-1-}$ mutants, the ectopic and proliferating GCPs express markers of EGL progenitors such as Math1. Thus, GCs that proliferate outside the EGL in Plexin-B2 ${ }^{-/-}$mice differ from EGL GCPs because they do not express high levels of Math1 and Barhl1 but express markers of differentiated granule cells such as TAG-1, Sema6A, and Dcx.

Shh is the strongest known mitogen for GCPs (Dahmane and Ruiz i Altaba, 1999; Wechsler-Reya and Scott, 1999). In Plexin$B 2^{-/-}$mutants, the abnormal timing of GCP proliferation together with the increased proliferation at P13-P15 could be attributable to a deregulation of Shh signaling. However, we could not detect any modification of the expression of Shh, its receptors Patched and Smoothened, or of its effectors Gli1 and Nmyc (neuroblastoma myc-related oncogene) in Plexin-B2 $2^{-/-}$cerebella (data not shown).

Impaired neuronal differentiation and perturbed cell proliferation, in particular activation of mitosis in differentiated neurons, were proposed to lead to cell death (Yang et al., 2001; Cicero and Herrup, 2005). In mice lacking cyclin D2 (Huard et al., 1999) or NeuroD (Miyata et al., 1999), there is an increased GC death. Last, in granule cell cultures from Pax6-deficient mice (Swanson et al., 2005) cells expressing the neuronal marker $\beta$ III-tubulin appear to proliferate and die. Our results, together with recent analysis of retinoblastoma conditional knock-out mice (MacPherson et al., 2003; Wu et al., 2003), show that sustained cell cycle activation in differentiated neurons does not necessarily trigger cell death. This absence of increased cell death together with the maintenance of an apparently correct cerebellar circuitry may explain the lack of noticeable behavioral defects in Plexin$B 2^{-1-}$ mice.

In summary, we propose that the abnormal morphogenesis in the Plexin-B2 $2^{-1-}$ mutant cerebellum most likely arises from a premature granule cell differentiation/migration and loss of feedback inhibition of proliferation. A disruption of the proliferation/ differentiation balance in the neural tube could also explain neural tube closure defects observed in Plexin-B2 $2^{-/-}$embryos, but this will have to be explored in more detail (for review, see Copp et al., 2003).

\section{How could Plexin-B2 control granule cell differentiation?}

In the EGL, Plexin-B2 is expressed by proliferating GCPs, and its downregulation coincides with the initiation of granule cell differentiation. In Plexin-B2-deficient mice, the differentiation of GCPs could start prematurely allowing cells to initiate their inward migration before the completion of their last division. Thus, a possible model of action for Plexin-B2 is that, after binding its ligand, expressed by GCPs themselves or by neighboring cells (e.g., meninges or Bergmann glia), Plexin-B2 may block the differentiation of GCPs, by preventing the appearance of neurites and blocking the migration machinery. Sema4D, a putative ligand for Plexin-B2 (Masuda et al., 2004), is not expressed in the developing cerebellar cortex (Moreau-Fauvarque et al., 2003). We show here that six class 4 semaphorins are expressed at variable levels in the postnatal cerebellar cortex. We also show that the cerebella organization in mice deficient for Sema4A, Sema4D, or both Sema4A and Sema4D was similar to that in wild-type mice. These results show that additional ligands are involved. Their identification will require generating mice deficient for several class 4 semaphorins, and other yet unknown ligands may also be involved. Two additional physiological partners could be the tyrosine kinase receptors MET and ErbB2, both of which bind to Plexin-B2 (Giordano et al., 2002; Swiercz et al., 2004). However, a partial loss-of-function MET mouse mutant only has a weak cerebella phenotype that does not resemble the Plexin-B2 phenotype (Ieraci et al., 2002), and ErbB2 is not expressed by GCPs in the EGL (Patten et al., 2003).

Cultured granule cells rapidly exit the cell cycle unless they are allowed to reaggregate, in which case their proliferation is maintained (Gao et al., 1991). Because Plexin-B2 is slightly homophilic (Hartwig et al., 2005), the absence of Plexin-B2 might affect proliferation of granule cells indirectly by affecting their aggregation. The expanded distribution of proliferating precursors cells in Plexin- $B 2^{-/-}$cerebella is consistent with this interpretation.

There is mounting evidence that proteins controlling cytoskeletal dynamics play a key role during neuronal proliferation, differentiation, and migration. This is well characterized for cyclin-dependent kinase 5 and its downstream effectors (Cicero and Herrup, 2005; Kawauchi et al., 2006) and the microtubuleassociated proteins Dcx and doublecortin-like kinase, all of which influence GC development (Deuel et al., 2006; Koizumi et al., 2006; Shu et al., 2006). Like all plexins, Plexin-B2 should ultimately act on the cytoskeletal structures and dynamics, presumably through regulation of GTPases (Driessens et al., 2001; Aurandt et al., 2002; Perrot et al., 2002; Swiercz et al., 2002) or integrins (Oinuma et al., 2004a,b).

Expression studies have shown that, in the developing CNS, Plexin-B1 mRNA is also highly expressed in proliferative regions (Worz-Feld et al., 2004) and often coexpressed with Plexin-B2. Thus, Plexin-B1 and Plexin-B2 function in some proliferating cells may be redundant. This could be the case for neuronal progenitors in the ventricular zone of the neocortex that seem unaffected by Plexin-B2 deficiency (A. C., unpublished data). It will be important to determine whether the other B-Plexins, Plexin-B1 
and Plexin-B3, also control the balance between proliferation and differentiation in vivo.

\section{References}

Alder J, Lee KJ, Jessell TM, Hatten ME (1999) Generation of cerebellar granule neurons in vivo by transplantation of BMP-treated neural progenitor cells. Nat Neurosci 2:535-540.

Artigiani S, Conrotto P, Fazzari P, Gilestro GF, Barberis D, Giordano S, Comoglio PM, Tamagnone L (2004) Plexin-B3 is a functional receptor for semaphorin 5A. EMBO Rep 5:710-714.

Aruga J, Inoue T, Hoshino J, Mikoshiba K (2002) Zic2 controls cerebellar development in cooperation with Zic1. J Neurosci 22:218-225.

Aurandt J, Vikis HG, Gutkind JS, Ahn N, Guan KL (2002) The semaphorin receptor plexin-B1 signals through a direct interaction with the Rhospecific nucleotide exchange factor, LARG. Proc Natl Acad Sci USA 99:12085-12090.

Blaess S, Corrales JD, Joyner AL (2006) Sonic hedgehog regulates Gli activator and repressor functions with spatial and temporal precision in the $\mathrm{mid} / \mathrm{hindbrain}$ region. Development 133:1799-1809.

Cheng HJ, Bagri A, Yaron A, Stein E, Pleasure SJ, Tessier-Lavigne M (2001) Plexin-A3 mediates semaphorin signaling and regulates the development of hippocampal axonal projections. Neuron 32:249-263.

Chenn A, Walsh CA (2002) Regulation of cerebral cortical size by control of cell cycle exit in neural precursors. Science 297:365-369.

Choi Y, Borghesani PR, Chan JA, Segal RA (2005) Migration from a mitogenic niche promotes cell-cycle exit. J Neurosci 25:10437-10445.

Cicero S, Herrup K (2005) Cyclin-dependent kinase 5 is essential for neuronal cell cycle arrest and differentiation. J Neurosci 25:9658-9668.

Copp AJ, Greene ND, Murdoch JN (2003) The genetic basis of mammalian neurulation. Nat Rev Genet 4:784-793.

Corrales JD, Blaess S, Mahoney EM, Joyner AL (2006) The level of sonic hedgehog signaling regulates the complexity of cerebellar foliation. Development 133:1811-1821.

Dahmane N, Ruiz i Altaba A (1999) Sonic hedgehog regulates the growth and patterning of the cerebellum. Development 126:3089-3100.

de Diego I, Kyriakopoulou K, Karagogeos D, Wassef M (2002) Multiple influences on the migration of precerebellar neurons in the caudal medulla. Development 129:297-306.

Deuel TA, Liu JS, Corbo JC, Yoo SY, Rorke-Adams LB, Walsh CA (2006) Genetic interactions between doublecortin and doublecortin-like kinase in neuronal migration and axon outgrowth. Neuron 49:41-53.

Driessens MH, Hu H, Nobes CD, Self A, Jordens I, Goodman CS, Hall A (2001) Plexin-B semaphorin receptors interact directly with active Rac and regulate the actin cytoskeleton by activating Rho. Curr Biol 11:339-344.

Friedel RH, Plump A, Lu X, Spilker K, Jolicoeur C, Wong K, Venkatesh TR, Yaron A, Hynes M, Chen B, Okada A, McConnell SK, Rayburn H, TessierLavigne M (2005) Gene targeting using a promoterless gene trap vector ("targeted trapping") is an efficient method to mutate a large fraction of genes. Proc Natl Acad Sci USA 102:13188-13193.

Gao WO, Heintz N, Hatten ME (1991) Cerebellar granule cell neurogenesis is regulated by cell-cell interactions in vitro. Neuron 6:705-715.

Gherardi E, Love CA, Esnouf RM, Jones EY (2004) The sema domain. Curr Opin Struct Biol 14:669-678.

Giordano S, Corso S, Conrotto P, Artigiani S, Gilestro G, Barberis D, Tamagnone L, Comoglio PM (2002) The semaphorin 4D receptor controls invasive growth by coupling with Met. Nat Cell Biol 4:720-724.

Graus-Porta D, Blaess S, Senften M, Littlewood-Evans A, Damsky C, Huang Z, Orban P, Klein R, Schittny JC, Muller U (2001) Beta1-class integrins regulate the development of laminae and folia in the cerebral and cerebellar cortex. Neuron 31:367-379.

Gu C, Yoshida Y, Livet J, Reimert DV, Mann F, Merte J, Henderson CE, Jessell TM, Kolodkin AL, Ginty DD (2005) Semaphorin 3E and plexin-D1 control vascular pattern independently of neuropilins. Science 307:265-268.

Hartwig C, Veske A, Krejcova S, Rosenberger G, Finckh U (2005) Plexin B3 promotes neurite outgrowth, interacts homophilically, and interacts with Rin. BMC Neurosci 6:53.

Huard JM, Forster CC, Carter ML, Sicinski P, Ross ME (1999) Cerebellar histogenesis is disturbed in mice lacking cyclin D2. Development 126:1927-1935.

Ieraci A, Forni PE, Ponzetto C (2002) Viable hypomorphic signaling mu- tant of the Met receptor reveals a role for hepatocyte growth factor in postnatal cerebellar development. Proc Natl Acad Sci USA 99:15200-15205.

Kawauchi T, Chihama K, Nabeshima Y, Hoshino M (2006) Cdk5 phosphorylates and stabilizes p27kipl contributing to actin organization and cortical neuronal migration. Nat Cell Biol 8:17-26.

Kerjan G, Dolan J, Haumaitre C, Schneider-Maunoury S, Fujisawa H, Mitchell KJ, Chedotal A (2005) The transmembrane semaphorin Sema6A controls cerebellar granule cell migration. Nat Neurosci 8:1516-1524.

Klein RS, Rubin JB, Gibson HD, DeHaan EN, Alvarez-Hernandez X, Segal RA, Luster AD (2001) SDF-1 alpha induces chemotaxis and enhances Sonic hedgehog-induced proliferation of cerebellar granule cells. Development 128:1971-1981.

Koizumi H, Tanaka T, Gleeson JG (2006) Doublecortin-like kinase functions with doublecortin to mediate fiber tract decussation and neuronal migration. Neuron 49:55-66.

Kruger RP, Aurandt J, Guan KL (2005) Semaphorins command cells to move. Nat Rev Mol Cell Biol 6:789-800.

Kumanogoh A, Suzuki K, Ch'ng E, Watanabe C, Marukawa S, Takegahara N, Ishida I, Sato T, Habu S, Yoshida K, Shi W, Kikutani H (2002) Requirement for the lymphocyte semaphorin, CD100, in the induction of antigen-specific $T$ cells and the maturation of dendritic cells. J Immunol 169:1175-1181.

Kumanogoh A, Shikina T, Suzuki K, Uematsu S, Yukawa K, Kashiwamura S, Tsutsui H, Yamamoto M, Takamatsu H, Ko-Mitamura EP, Takegahara N, Marukawa S, Ishida I, Morishita H, Prasad DV, Tamura M, Mizui M, Toyofuku T, Akira S, Takeda K, Okabe M, Kikutani H (2005) Nonredundant roles of Sema4A in the immune system: defective T cell priming and Th1/Th2 regulation in Sema $4 \mathrm{~A}$-deficient mice. Immunity 22:305-316.

Leighton PA, Mitchell KJ, Goodrich LV, Lu X, Pinson K, Scherz P, Skarnes WC, Tessier-Lavigne M (2001) Defining brain wiring patterns and mechanisms through gene trapping in mice. Nature 410:174-179.

Li S, Qiu F, Xu A, Price SM, Xiang M (2004) Barhll regulates migration and survival of cerebellar granule cells by controlling expression of the neurotrophin-3 gene. J Neurosci 24:3104-3114.

Lindholm D, Hamner S, Zirrgiebel U (1997) Neurotrophins and cerebellar development. Perspect Dev Neurobiol 5:83-94.

Lu Q, Sun EE, Klein RS, Flanagan JG (2001) Ephrin-B reverse signaling is mediated by a novel PDZ-RGS protein and selectively inhibits $G$ proteincoupled chemoattraction. Cell 105:69-79.

Lumpkin EA, Collisson T, Parab P, Omer-Abdalla A, Haeberle H, Chen P, Doetzlhofer A, White P, Groves A, Segil N, Johnson JE (2003) Math1driven GFP expression in the developing nervous system of transgenic mice. Gene Expr Patterns 3:389-395.

Ma Q, Jones D, Borghesani PR, Segal RA, Nagasawa T, Kishimoto T, Bronson RT, Springer TA (1998) Impaired B-lymphopoiesis, myelopoiesis, and derailed cerebellar neuron migration in CXCR4- and SDF-1-deficient mice. Proc Natl Acad Sci USA 95:9448-9453.

MacPherson D, Sage J, Crowley D, Trumpp A, Bronson RT, Jacks T (2003) Conditional mutation of Rb causes cell cycle defects without apoptosis in the central nervous system. Mol Cell Biol 23:1044-1053.

Mares V, Lodin Z (1970) The cellular kinetics of the developing mouse cerebellum. II. The function of the external granular layer in the process of gyrification. Brain Res 23:343-352.

Marillat V, Cases O, Nguyen-Ba-Charvet KT, Tessier-Lavigne M, Sotelo C, Chedotal A (2002) Spatiotemporal expression patterns of slit and robo genes in the rat brain. J Comp Neurol 442:130-155.

Masuda K, Furuyama T, Takahara M, Fujioka S, Kurinami H, Inagaki S (2004) Sema4D stimulates axonal outgrowth of embryonic DRG sensory neurones. Genes Cells 9:821-829.

Millen KJ, Hui CC, Joyner AL (1995) A role for En-2 and other murine homologues of Drosophila segment polarity genes in regulating positional information in the developing cerebellum. Development 121:3935-3945.

Mitchell KJ, Pinson KI, Kelly OG, Brennan J, Zupicich J, Scherz P, Leighton PA, Goodrich LV, Lu X, Avery BJ, Tate P, Dill K, Pangilinan E, Wakenight P, Tessier-Lavigne M, Skarnes WC (2001) Functional analysis of secreted and transmembrane proteins critical to mouse development. Nat Genet 28:241-249.

Miyata T, Maeda T, Lee JE (1999) NeuroD is required for differentiation of the granule cells in the cerebellum and hippocampus. Genes Dev 13:1647-1652. 
Moreau-Fauvarque C, Kumanogoh A, Camand E, Jaillard C, Barbin G, Boquet I, Love C, Jones EY, Kikutani H, Lubetzki C, Dusart I, Chedotal A (2003) The transmembrane semaphorin Sema4D/CD100, an inhibitor of axonal growth, is expressed on oligodendrocytes and upregulated after CNS lesion. J Neurosci 23:9229-9239.

Ohnuma S, Harris WA (2003) Neurogenesis and the cell cycle. Neuron 40:199-208.

Oinuma I, Katoh H, Negishi M (2004a) Molecular dissection of the semaphorin 4D receptor plexin-B1-stimulated R-Ras GTPase-activating protein activity and neurite remodeling in hippocampal neurons. J Neurosci 24:11473-11480.

Oinuma I, Ishikawa Y, Katoh H, Negishi M (2004b) The Semaphorin 4D receptor Plexin-B1 is a GTPase activating protein for R-Ras. Science 305:862-865

Pasterkamp RJ, Peschon JJ, Spriggs MK, Kolodkin AL (2003) Semaphorin 7A promotes axon outgrowth through integrins and MAPKs. Nature 424:398-405.

Patten BA, Peyrin JM, Weinmaster G, Corfas G (2003) Sequential signaling through Notch 1 and erbB receptors mediates radial glia differentiation. J Neurosci 23:6132-6140.

Perala NM, Immonen T, Sariola H (2005) The expression of plexins during mouse embryogenesis. Gene Expr Patterns 5:355-362.

Perrot V, Vazquez-Prado J, Gutkind JS (2002) Plexin B regulates Rho through the guanine nucleotide exchange factors leukemia-associated Rho GEF (LARG) and PDZ-RhoGEF. J Biol Chem 277:43115-43120.

Shu T, Tseng HC, Sapir T, Stern P, Zhou Y, Sanada K, Fischer A, Coquelle FM, Reiner O, Tsai LH (2006) Doublecortin-like kinase controls neurogenesis by regulating mitotic spindles and $\mathrm{M}$ phase progression. Neuron 49:25-39.

Suto F, Ito K, Uemura M, Shimizu M, Shinkawa Y, Sanbo M, Shinoda T, Tsuboi M, Takashima S, Yagi T, Fujisawa H (2005) Plexin-a4 mediates axon-repulsive activities of both secreted and transmembrane semaphorins and plays roles in nerve fiber guidance. J Neurosci 25:3628-3637.

Swanson DJ, Tong Y, Goldowitz D (2005) Disruption of cerebellar granule cell development in the Pax6 mutant, Sey mouse. Brain Res Dev Brain Res 160:176-193.

Swiercz JM, Kuner R, Behrens J, Offermanns S (2002) Plexin-B1 directly interacts with PDZ-RhoGEF/LARG to regulate RhoA and growth cone morphology. Neuron 35:51-63.

Swiercz JM, Kuner R, Offermanns S (2004) Plexin-B1/RhoGEF-mediated RhoA activation involves the receptor tyrosine kinase ErbB-2. J Cell Biol 165:869-880

Tamagnone L, Artigiani S, Chen H, He Z, Ming GI, Song H, Chedotal A, Winberg ML, Goodman CS, Poo M, Tessier-Lavigne M, Comoglio PM (1999) Plexins are a large family of receptors for transmembrane, secreted, and GPI-anchored semaphorins in vertebrates. Cell 99:71-80.

Toyofuku T, Yoshida J, Sugimoto T, Zhang H, Kumanogoh A, Hori M, Kikutani H (2005) FARP2 triggers signals for Sema3A-mediated axonal repulsion. Nat Neurosci 8:1712-1719.

Vilz TO, Moepps B, Engele J, Molly S, Littman DR, Schilling K (2005) The SDF-1/CXCR4 pathway and the development of the cerebellar system. Eur J Neurosci 22:1831-1839.

Wechsler-Reya RJ, Scott MP (1999) Control of neuronal precursor proliferation in the cerebellum by Sonic Hedgehog. Neuron 22:103-114.

Wingate R (2005) Math-Map(ic)s. Neuron 48:1-4.

Worz-Feld T, Puschel AW, Offermanns S, Kuner R (2004) Plexin-B family members demonstrate non-redundant expression patterns in the developing mouse nervous system: an anatomical basis for morphogenetic effects of Sema4D during development. Eur J Neurosci 19:2622-2632.

Wu L, de Bruin A, Saavedra HI, Starovic M, Trimboli A, Yang Y, Opavska J, Wilson P, Thompson JC, Ostrowski MC, Rosol TJ, Woollett LA, Weinstein M, Cross JC, Robinson ML, Leone G (2003) Extra-embryonic function of $\mathrm{Rb}$ is essential for embryonic development and viability. $\mathrm{Na}$ ture 421:942-947.

Yacubova E, Komuro H (2003) Cellular and molecular mechanisms of cerebellar granule cell migration. Cell Biochem Biophys 37:213-234.

Yang Y, Geldmacher DS, Herrup K (2001) DNA replication precedes neuronal cell death in Alzheimer's disease. J Neurosci 21:2661-2668.

Yaron A, Huang PH, Cheng HJ, Tessier-Lavigne M (2005) Differential requirement for Plexin-A3 and -A4 in mediating responses of sensory and sympathetic neurons to distinct class 3 Semaphorins. Neuron 45:513-523.

Zou YR, Kottmann AH, Kuroda M, Taniuchi I, Littman DR (1998) Function of the chemokine receptor CXCR4 in haematopoiesis and in cerebellar development. Nature 393:595-599. 